1999-05-01

\title{
Cryosphere applications of NSCAT data
}

David G. Long

david_long@byu.edu

Mark R. Drinkwater

Follow this and additional works at: https://scholarsarchive.byu.edu/facpub

Part of the Electrical and Computer Engineering Commons

\section{Original Publication Citation}

Long, D. G., and M. R. Drinkwater. "Cryosphere Applications of NSCAT Data." Geoscience and Remote Sensing, IEEE Transactions on 37.3 (1999): 1671-84

\section{BYU ScholarsArchive Citation}

Long, David G. and Drinkwater, Mark R., "Cryosphere applications of NSCAT data" (1999). Faculty Publications. 622.

https://scholarsarchive.byu.edu/facpub/622

This Peer-Reviewed Article is brought to you for free and open access by BYU ScholarsArchive. It has been accepted for inclusion in Faculty Publications by an authorized administrator of BYU ScholarsArchive. For more information, please contact ellen_amatangelo@byu.edu. 


\title{
Cryosphere Applications of NSCAT Data
}

\author{
David G. Long, Senior Member, IEEE, and Mark R. Drinkwater, Member, IEEE
}

\begin{abstract}
Though designed to measure vector winds over the ocean, new imaging techniques facilitate the use of NASA scatterometer data (NSCAT) in cryosphere studies. NSCAT provides data of unprecedented coverage, resolution, and quality which, when coupled with the scatterometer image reconstruction with filtering (SIRF) algorithm, enables images of $\sigma^{\circ}$ at resolutions approaching $8 \mathrm{~km}$ over stationary targets. Such images are useful in ice mapping and classification, and multidecadal studies are possible by comparison with Seasat Scatterometer (SASS) data. The utility of NSCAT data in polar ice studies is illustrated through a review of two cryosphere applications of NSCAT data: 1) sea-ice mapping and tracking and 2) ice-sheet change in Greenland and Antarctica. The wide swath and frequent revisit, coupled with incidence and azimuth angle diversity makes NSCAT data very effective in mapping the extent of sea-ice. In Greenland, snow and ice "facies" are clearly delineated on the basis of the seasonally dependent radar backscattering cross section, due to sensitivity of radar backscatter to diagenetic changes occurring at and beneath the surface. Comparison of NSCAT and SASS data enables study of change in Greenland between 1978 and 1996.
\end{abstract}

Index Terms - Ice sheets, polar, radar, scatterometer, sea-ice.

\section{INTRODUCTION}

$\mathbf{T}$ HE CRYOSPHERE, consisting of the polar sea ice and large land ice sheets, plays a crucial role in regulating global climate. Sea ice acts as an insulating layer between the relatively warm ocean and cool atmosphere and increases the albedo of the polar oceans during winter, thereby controlling the radiation balance [6], [7], [48]. Large continental ice sheets covering Greenland and Antarctica add to the polar heat sink effect by their additional influence upon planetary albedo and are important freshwater storage locations [4]. Furthermore, ice sheets are sensitive indicators of global climate change. Controversy over the relationship between global warming and changes in the Greenland ice sheet [1], [10], [72] in the northern hemisphere and the disintegration of the northernmost Antarctic ice shelves [11], [61], [62] in the southern hemisphere make it imperative to measure the current state of ice sheet mass balance and the timescales of variability in both snow accumulation and ablation. Hence, monitoring of polar ice is of particular interest to the remote sensing and climate change research communities.

Manuscript received May 19, 1998; revised January 7, 1998. This work was completed at the Brigham Young University Microwave Earth Remote Sensing Laboratory and at the Jet Propulsion Laboratory under contract with the National Aeronautic and Space Administration.

D. G. Long is with the Electrical and Computer Engineering Department, Brigham Young University, Provo, UT 84602 USA (e-mail: long@ee.byu.edu).

M. R. Drinkwater is with the Jet Propulsion Laboratory, California Institute of Technology, Pasadena, CA 91109 USA (e-mail: mrd@pacific.jpl.nasa.gov).

Publisher Item Identifier S 0196-2892(99)03584-6.
A wind scatterometer is a radar remote sensing instrument designed to measure the normalized radar cross section $\left(\sigma^{\circ}\right)$ of the ocean's surface from which the near-surface wind over the ocean is inferred with the aid of a geophysical model function [49]. Scatterometers also make $\sigma^{\circ}$ measurements over land, vegetation, and ice surfaces. Until recently, these measurements were used primarily for calibrating the sensor. However, because they provide frequent, global observations, scatterometer measurements are also useful for the study of tropical rainforest (e.g., [27], [33], [46], [70]) and polar ice (e.g., [16], [20], [39], [45], [57], [69], [71]).

The NASA scatterometer (NSCAT) was successfully operated from September 1996 through June 1997 [5], [44], [49]. NSCAT made $14.6 \mathrm{GHz}$ measurements of $\mathrm{HH}-$ and VVpolarized $\sigma^{\circ}$ on ascending and descending orbits at various azimuth and incidence angles. The nominal $\sigma^{\circ}$ resolution is approximately $25 \mathrm{~km}$ with hexagonal resolution cells. Measurements were made over two $600-\mathrm{km}$ wide swaths separated by a $200-\mathrm{km}$ wide gap. The measurement geometry and timing were selected to optimize NSCAT's performance in its primary mission of long-term measurement of vector winds over the global oceans with full coverage of the global oceans at least once every three days. Most of the earth was observed multiple times during this period with the polar regions observed several times each day. This rapid repeat coverage can be combined with resolution enhancement algorithms to increase the utility of NSCAT data in polar ice studies.

This paper describes two particular areas of application of NSCAT data to cryosphere studies: 1) sea-ice mapping and 2) measurements of glacial ice in Greenland and Antarctica. Section II provides background and describes the resolution enhancement used in the data analysis. Section III gives an overview of the application of NSCAT to sea-ice extent mapping and motion detection. Section IV presents new results from studies of the Greenland ice sheet using NSCAT data. A summary discussion is provided in Section V.

\section{BACKGROUND}

The low spatial resolution of scatterometers is suitable for studying large-scale ocean phenomena. However, for some land and ice studies, the low intrinsic resolution can limit the utility of the data. The scatterometer image reconstruction with filter (SIRF) algorithm has been developed to enhance scatterometer image resolution by combining data from multiple passes of the satellite [24], [25], [47], [55]. It uses multiple $\sigma^{c}$ values to increase the effective resolution of the data.

Over a limited incidence angle range of $\left[20^{\circ}, 55^{\circ}\right], \mathrm{Ku}-$ band $\sigma^{\circ}$ (in $\mathrm{dB}$ ) is approximately a linear function of $\theta$

$$
\sigma^{\circ}(\theta)=A+B\left(\theta-40^{\circ}\right)
$$



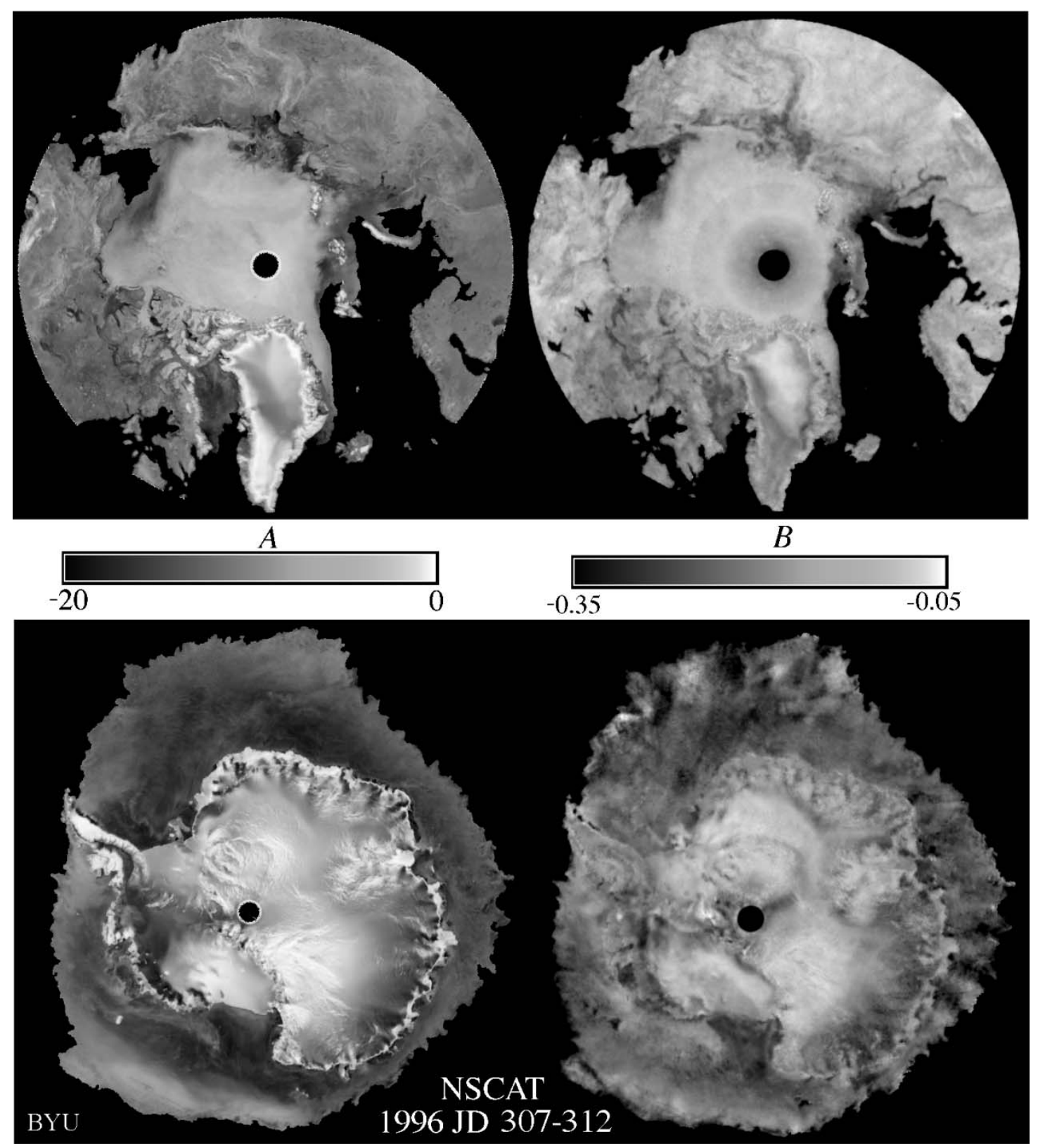

Fig. 1. SIRF $\mathcal{A}$ and $\mathcal{B}$ images of the polar regions generated from six days of NSCAT data. The NSCAT-derived RL ice mask [54] has been applied with regions identified as open ocean set to black.

where $\mathcal{A}$ and $\mathcal{B}$ are functions of surface characteristics, azimuth angle, and polarization. $\mathcal{A}$ is the $\sigma^{\circ}$ value at $40^{\circ}$ (mid swath) incidence and $\mathcal{B}$ describes the dependence of $\sigma^{\circ}$ on $\theta$. $\mathcal{A}$ and $\mathcal{B}$ provide valuable information about surface parameters. The SIRF algorithm simultaneously produces $\mathcal{A}$ and $\mathcal{B}$ images from several days (termed the "imaging period") of NSCAT $\sigma^{\circ}$ measurements. Sample NSCAT $\mathcal{A}$ and $\mathcal{B}$ images over the polar regions generated from six days of data are shown in Fig. 1.

Using the SIRF algorithm, dual polarization $\mathcal{A}$ and $\mathcal{B}$ images with an effective resolution of $8-10 \mathrm{~km}$ in the polar regions can be generated with six days of NSCAT data. NSCAT V pol images can be produced with only three days of data or less since there are more $\mathrm{V}$ pol antenna beams than $\mathrm{H}$ pol beams. However, for most studies, six days are used to ensure that the
$\mathrm{H}$ pol data provides enough coverage to create reconstructed images. Since the V pol images are reconstructed with more measurements, the qualities of the $\mathcal{A}$ and $\mathcal{B}$ estimates are superior to the $\mathrm{H}$ pol image.

The $\mathcal{A}$ and $\mathcal{B}$ data provide global images of the mean radar backscatter properties of the surface over the imaging period. The scatterometer-derived backscatter properties can then be related to ice and snow characteristics to study the seasonal evolution of polar ice regions.

\section{SEA-ICE MAPPING}

Sea-ice extent is a critical input parameter to global climate models and thus the need for monitoring the extent of sea ice. Sea-ice mapping is also needed for retrieval of ocean wind velocities from scatterometer measurements. If $\sigma^{\circ}$ measure- 


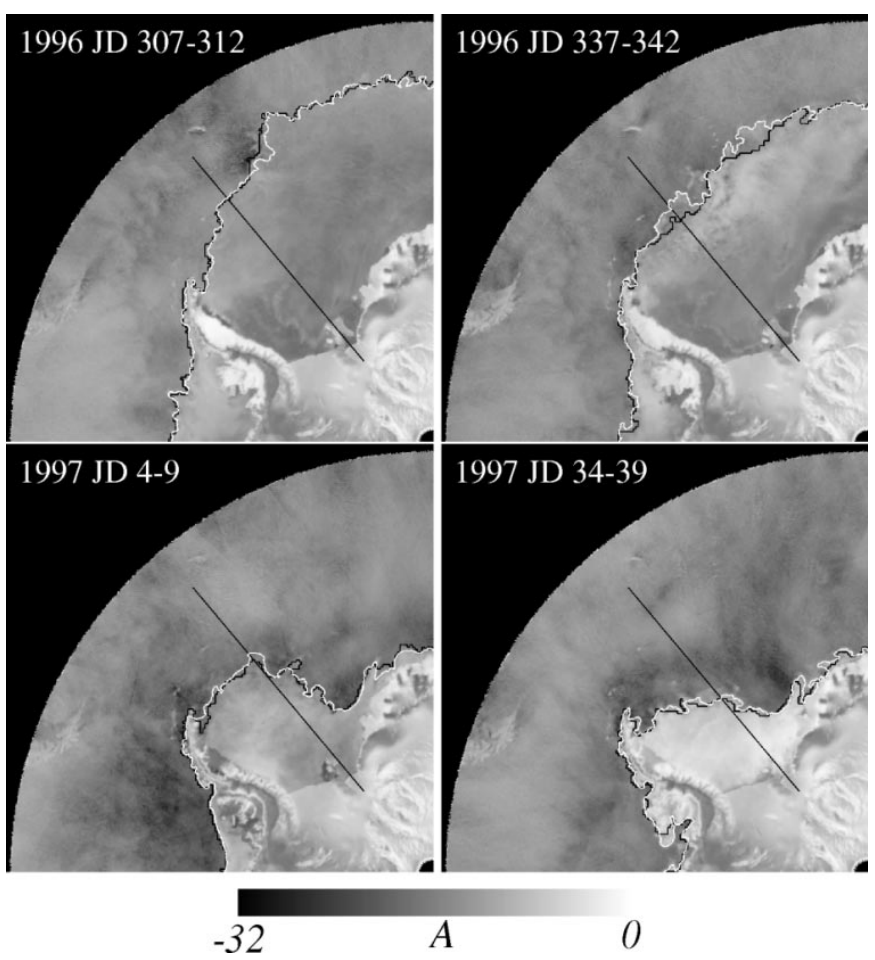

Fig. 2. SIRF $\mathcal{A}$ images over the Weddell Sea at four different times of the year. The NSCAT-derived ice extent based on the RL algorithm is shown as a white line. The SSM/I-derived $30 \%$ ice concentration ice edge is shown as a black line. Land ice shows up as very bright in these images. Radial lines denote the location of the plots in Fig. 3. A nonoptimum grayscale is used to enable visibility of the ice edges in the images.

ments over sea ice are included in the wind retrievals, the wind estimates are degraded. Thus, accurate knowledge of the sea ice margin location is also required for wind retrieval. Further, for sea ice applications, the masking of open ocean is required in order to study sea ice processes at the margin of the sea ice.

Scatterometer data is well suited for sea-ice mapping because of its rapid repeat coverage in the polar regions and reduced sensitivity to atmospheric effects. In contrast, special sensor microwave/imager (SSM/I) passive radiometer data (at 19, 37, and $85 \mathrm{GHz}$ ), which have traditionally been used for sea ice mapping, exhibit marked sensitivity to atmospheric water vapor content and precipitable water, particularly over the Antarctic ice pack [51]. In the following sections we consider several applications of NSCAT data for sea mapping including ice edge mapping, melt onset, motion tracking, and ice classification.

\section{A. Sea-Ice Extent Mapping}

While capable of determining the ice edge alone, NSCAT data can complement passive microwave observations of the ice margin. Several algorithms for discriminating between sea-ice and open ocean using scatterometer data have been developed, e.g., [54] and [71], among others. Using nonenhanced SASS data, Yueh et al. [71] demonstrate that $\mathrm{Ku}-$ band backscatter is effective in discriminating between open ocean and sea ice. Remund and Long [54] (denoted RL in the following) have developed an operational sea-ice extent algorithm based on enhanced resolution NSCAT data. The RL algorithm is being used for the reprocessing of NSCAT data to create ice-masked images similar to those in Fig. 1. These are used to eliminate ice contaminated measurements from the wind retrieval and for further sea ice studies.

A description of the RL algorithm is given in [54]. The RL algorithm uses the polarization ratio $\gamma=\mathcal{A}_{V} / \mathcal{A}_{H}$ and the incidence angle dependence $\left(\mathcal{B}_{V}\right)$ as the primary discrimination parameters since they are the most sensitive to the presence of sea ice. The open ocean typically exhibits a large $\gamma$ while sea ice has a small $\gamma$. Similarly, $\mathcal{B}_{V}$ for ice is typically greater than for the ocean due to combinations of rough surface and volume scattering. An initial set of classifications for each image pixel is made using adaptive thresholds based on the observed $\gamma$ and $\mathcal{B}_{V}$ distribution. Since regions of very low or high wind speeds can confuse the classification, the $\sigma^{\mathrm{C}}$ error standard deviation (denoted by $\kappa$ ), followed by some standard image processing is used to finalize the sea-ice extent map. The $\kappa$ image is a by-product of the SIRF algorithm as applied to NSCAT data and is the pixel-wise standard deviation of the difference between the measurements and their forward projection based on the $\mathcal{A}$ and $\mathcal{B}$ images [54]. Temporal variation and azimuthal modulation of $\sigma^{\circ}$ increase $\kappa$ which is thus larger over the ocean and relatively small over sea ice [23], [56]. The RL algorithm requires no a priori information and dynamically adapts to the temporal variability in the ice and ocean backscatter distributions. It can be used for both Arctic and Antarctic sea ice as illustrated in Fig. 1 where the derived ice edge is used to mask the SIRF images. A data set comprised of average ice extent images, produced every three days using a six-day overlapping imaging interval, has been generated for the full nine month NSCAT mission.

The RL algorithm sea-ice extent closely matches the SSM/Iderived NASA Team Algorithm [8], [9] 30\% ice concentration ice extent [54]. Fig. 2 compares the ice extent results derived using the RL algorithm with NSCAT data and the $30 \%$ ice concentration from SSM/I data. Fig. 2 shows several NSCAT-derived $\mathcal{A}_{V}$ images of the Weddell Sea. The Antarctic peninsula is clearly visible. Sea-ice extent estimates from NSCAT and the $30 \%$ ice concentration line from SSM/I data are shown. The values of NSCAT $\mathcal{A}_{V}$ and $\mathcal{B}_{V}$ and the SSM/Iderived ice concentration along the radial lines in this figure are shown in Figs. 3 and 4. There is a clear correlation between the NSCAT $\mathcal{A}_{V}$ and $\mathcal{B}_{V}$ values and the SSM/I ice concentrations. The differences are addressed in the following discussion.

Comparing the seasonal area of Antarctic sea-ice extent computed from NSCAT and SSM/I suggests that there are seasonal biases in the two ice edges. Fig. 5 compares the seasonal ice extent computed from SSM/I and from NSCAT over the NSCAT mission time period. The general trends in the area for both NSCAT and NSIDC signatures are very similar with the annual melt cycle along with a portion of the autumn freeze-up evident. Note that these values show the area of the ice extent rather than the total ice area since polynya contributions were removed and are not considered here. These results are similar to those of [30] and [50] in which the ice extent was computed using the scanning multichannel 

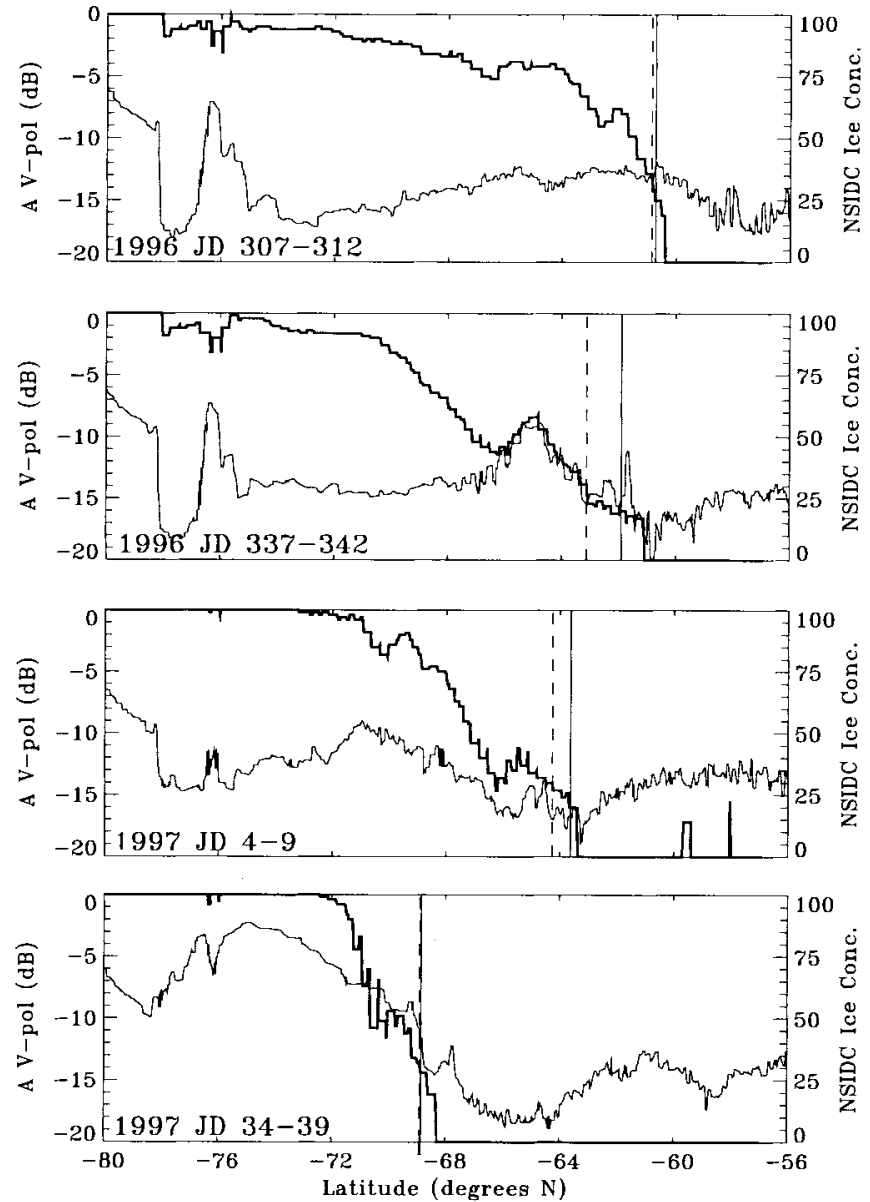

Fig. 3. Plots of NSCAT V-pol $\mathcal{A}$ (thin line) and SSM/I-derived ice concentration (thick line) versus latitude along the radial lines in Fig. 2. Vertical lines denote the NSCAT ice edge (solid line) and the $30 \%$ ice concentration ice edge (dashed line).

microwave radiometer (SMMR) from 1978 to 1987 although the maximum and minimum of the cycle were more extreme in 1996 to 1997 . We note that the areas differ the most during the ice retreat and advance phases. During ice retreat, the NSCAT estimated ice extent is generally greater than the SSM/I $30 \%$ ice concentration extent. During the ice growth phase, the $\mathrm{SSM} / \mathrm{I}$ ice extent is generally greater than NSCAT. Fetterer et al. [29] observed a similar trend in comparing SSM/I and Geosat radar altimeter ice edges.

$\mathrm{SSM} / \mathrm{I}$ has been found to be errant in discriminating the outer ice margin during periods of rapid ice advance and retreat, depending on the nature of ice dynamics and ice characteristics which accompany these periods. During thermodynamic ice edge advance (under rapid ice growth) the emissivity of new ice can confuse the NASA Team Algorithm for retrieving ice concentration and may result in erroneous ice concentration estimates [12], [66]. Similarly, summer melt can make the snow cover on Antarctic sea ice wet, resulting in underestimates of ice concentration and thereby biasing the $30 \%$ ice concentration ice estimate southward as suggested by Figs. 3-5.

We suggest that during periods of rapid ice growth and retreat when the ice signature is evolving rapidly, active
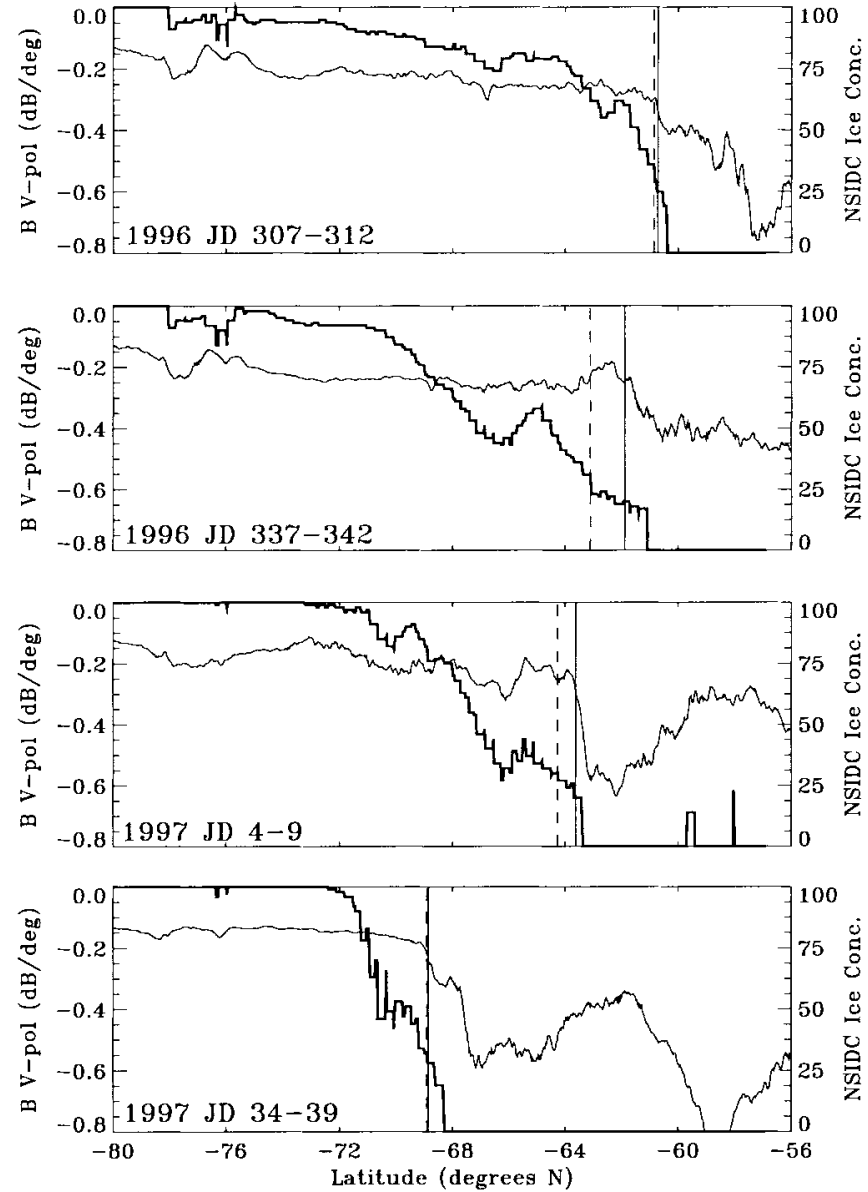

Fig. 4. Plots of NSCAT V-pol $\mathcal{B}$ (thin line) and SSM/I-derived ice concentration (thick line) versus latitude along the radial lines in Fig. 2. Vertical lines denote the NSCAT ice edge (solid line) and the $30 \%$ ice concentration ice edge (dashed line).

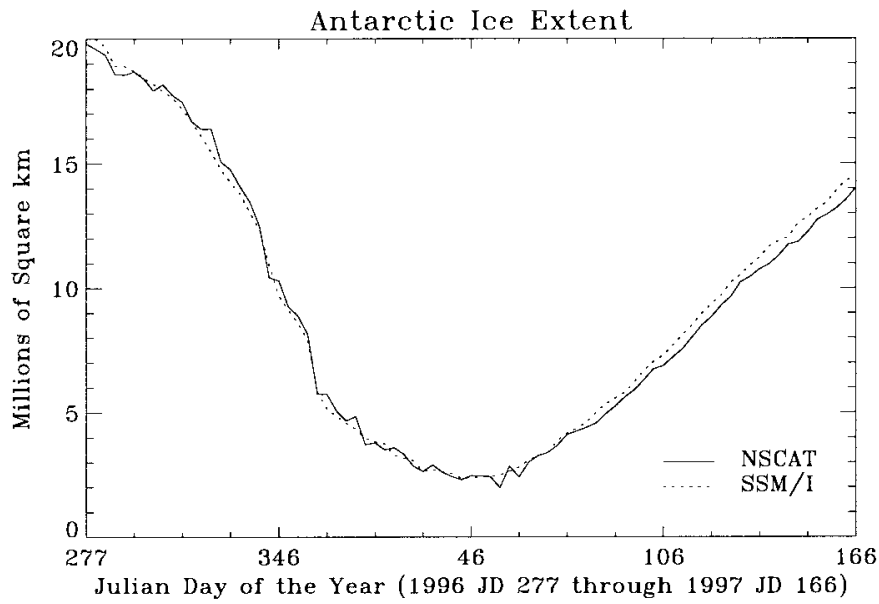

Fig. 5. Seasonal Antarctic sea-ice extent in square kilometers using the RL algorithm on NSCAT data and the NASA Team algorithm ice concentration algorithm on SSM/I data with the edge defined at $30 \%$ ice concentration. The data set extends from 1996, JD 277-282 to 1997, JD 166-171. The first Julian day of each imaging period is represented on the horizontal axis.

(radars) and passive sensors have different sensitivities and that by coupling scatterometer and radiometer data the accuracy of ice maps and ice classifications can be improved [13]. 


\section{B. Melt Onset Mapping}

Summer melting in the polar regions can significantly affect the global albedo, resulting in a positive feedback effect [7]. In particular, the length of the summer melt in the Arctic influences the seasonal sea ice budget [68]. Monitoring the timing and a real extent of summer melting is thus of great interest in weather and climate studies.

While the NSCAT data set does not cover the summer months in the northern hemisphere, the melt onset in the Arctic can be effectively studied using NSCAT data. During the winter months, moisture levels in the snow cover are negligible. As a result, the snow layer on the ice is essentially transparent at Ku-band [32]. However, as the surface temperature increases and the water content rises during early spring, forward scattering from the wet snow surface increases, thereby decreasing the $\mathcal{A}$ values [21]. This temperature-driven change in the scattering results in a significant change in the surface backscatter, suggesting that scatterometer measurements can be used to monitor the summer melt. As an example, Fig. 6 illustrates plots of temperature, precipitation, $\mathcal{A}_{V}$, and $\mathcal{B}_{V}$ versus time near Mould Bay. The temperature and precipitation record is from land-sited observations in Mould Bay while the backscatter measurements are made in McClure Strait just south of the land observations. While there are limitations in this type of comparison, there is a clear correlation between the backscatter and weather conditions. Prior to the mean air temperatures exceeding $-5^{\circ}$, precipitation in the Mould Bay region largely results in dry snow accumulation on the surface of the ice. Peaks in precipitation prior to day 148 do not significantly influence the $\mathcal{A}_{V}$ and $\mathcal{B}_{V}$ values due to the transparency of the dry snow. After day 148 when temperatures approach $0{ }^{\circ} \mathrm{C}$, an abrupt reduction in $\mathcal{A}_{V}$ occurs as surface melting begins. The gradual decline in $\mathcal{A}_{V}$ from near midwinter (JD 20) through the onset of melting is attributable to a small increase in permittivity and loss in the sea ice. Since the sea ice in this area is largely comprised of fast ice of low salinity, the influence of the varying permittivity and loss has only a small impact on the backscatter. This is in contrast to regions of seasonal ice where thermal dependence in complex permittivity can be expressed more clearly as reductions in the $\mathcal{A}_{V}$ value with seasonally increasing temperatures.

Using similar data from SASS Winebrenner et al. [68] and Drinkwater [21] demonstrated that Ku-band scatterometer data could be effective in inferring the timing and a real extent of melting in the Arctic. Following [68], Fig. 7 illustrates a sequence of NSCAT $\mathcal{A}_{V}$ images of a region in the Beaufort Sea. On the left edge of each image panel is the north coast of Alaska, with Mackenzie Bay at the lower left. Along the bottom edge of the image are the west coasts of Banks and Prince Patrick Islands in the Canadian Archipelago. The McClure Strait region from which Fig. 6 is derived is centered on the bottom edge of each panel. The low $\sigma^{\circ}$ (dark) region fringing the Alaskan and Canadian coast represents the seasonal sea ice cover while the higher $\sigma^{\circ}$ (lighter) area to the right is the perennial ice pack. On the coastline, melting progresses eastward along the North Slope of Alaska. The
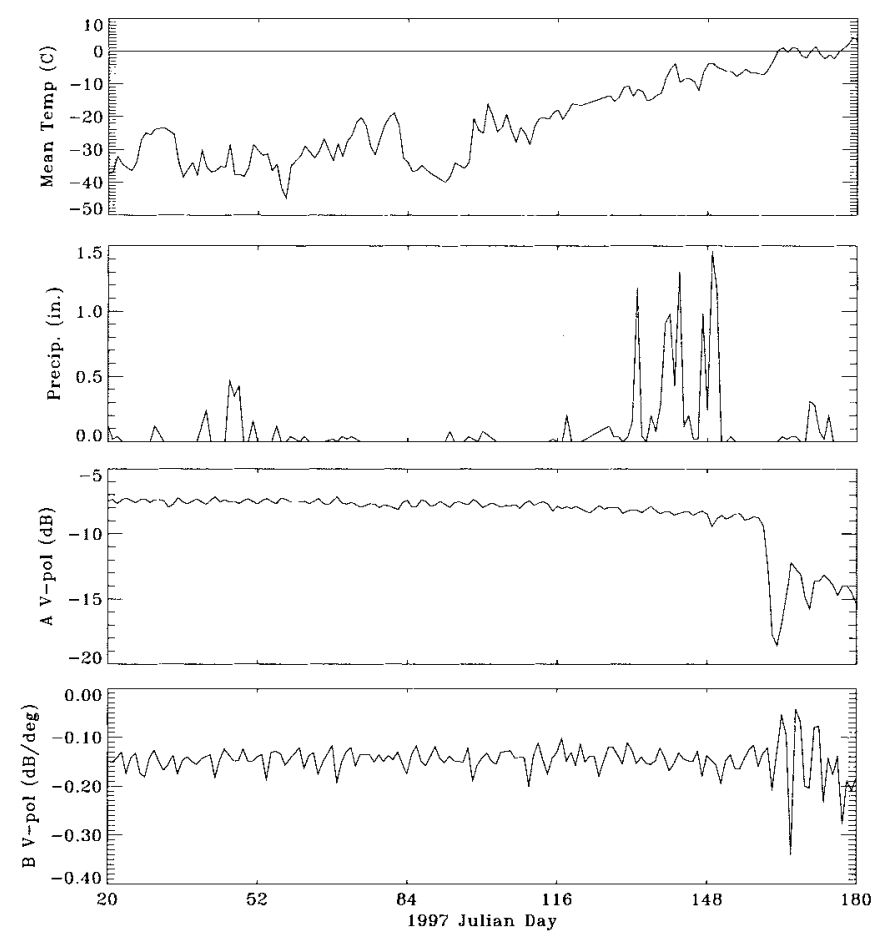

Fig. 6. Plot of various parameters versus Julian day. (top) Mean temperature measured at Mould Bay, Canada. (second from top) Daily precipitation at Mould Bay. (second from bottom) NSCAT $\mathcal{A}_{V}$ estimated using a one-day sliding window from a $1^{\circ}$ latitude $\times 2^{\circ}$ longitude ocean area just south of Mould Bay in the McClure Strait. The ocean area is centered at $74^{\circ} \mathrm{N}$ $119.5^{\circ} \mathrm{W}$ (bottom) NSCAT $\mathcal{B}_{V}$ in the ocean area.

expression of this melting appears in the fifth panel from the left on the top row as the appearance of a dark swath (low $\mathcal{A}_{V}$ value) along the northern margin of the Brooks Range. Incursions of warm air along the northern perimeter of the mountain chain cause melting and the appearance of surface wetness on frozen tundra lakes in the region. This is clearly reflected in the dramatic, though temporary, reduction in the $\sigma^{\circ}$ values over the North Slope. For sea ice, the area of seasonal sea ice experiencing snow surface melting first expands progressively eastward from the Chukchi sea. This is most evident in the right-most panel of the second row where the regions of the highest fraction of seasonal ice appear to be experiencing melt along the entire northern coastline. A distinctive melt front is evident between the region melting to the south and the unaffected perennial pack to the north. In the lower row of panels, the melt moves northward to encompass the entire region. The onset of snow surface melt is finally accompanied by the disappearance of seasonal ice from the Mackenzie Bay area, as clearly shown in the lower right panels where the open water is black with $\mathcal{A}_{V}$ less than $-20 \mathrm{~dB}$.

\section{Sea Ice Motion Tracking}

Satellite observation of sea ice motion aids in the monitoring of the ice dynamics for climate change studies and ship routing applications. Various techniques of automated ice tracking have been developed using high-resolution microwave and visible wavelength data, which are now routinely applied to tracking Arctic sea ice [34], [38]. These cross-correlation 


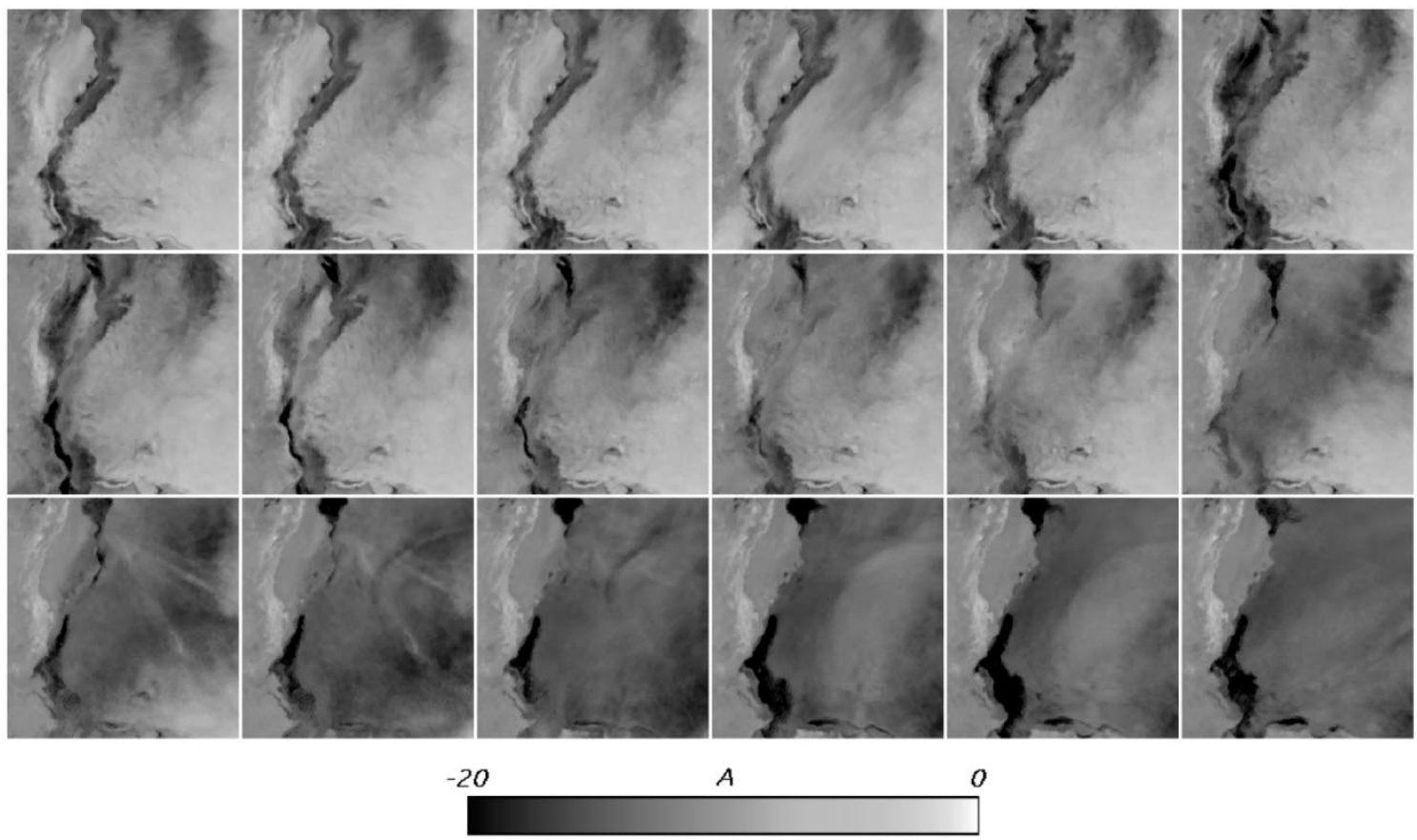

Fig. 7. Sequence of NSCAT $\mathcal{A}_{V}$ images of a small region in the Arctic Ocean. Each image uses six days of NSCAT data. Images are indexed from left to right, top to bottom. The first image (upper left) corresponds to JD 121-126, 1997, with images centered every three days. The last image (lower right) corresponds to JD $172-177,1997$. The images are centered at $70^{\circ} \mathrm{N}$ and $225^{\circ} \mathrm{E}$. The north coast of Alaska is visible to the left.

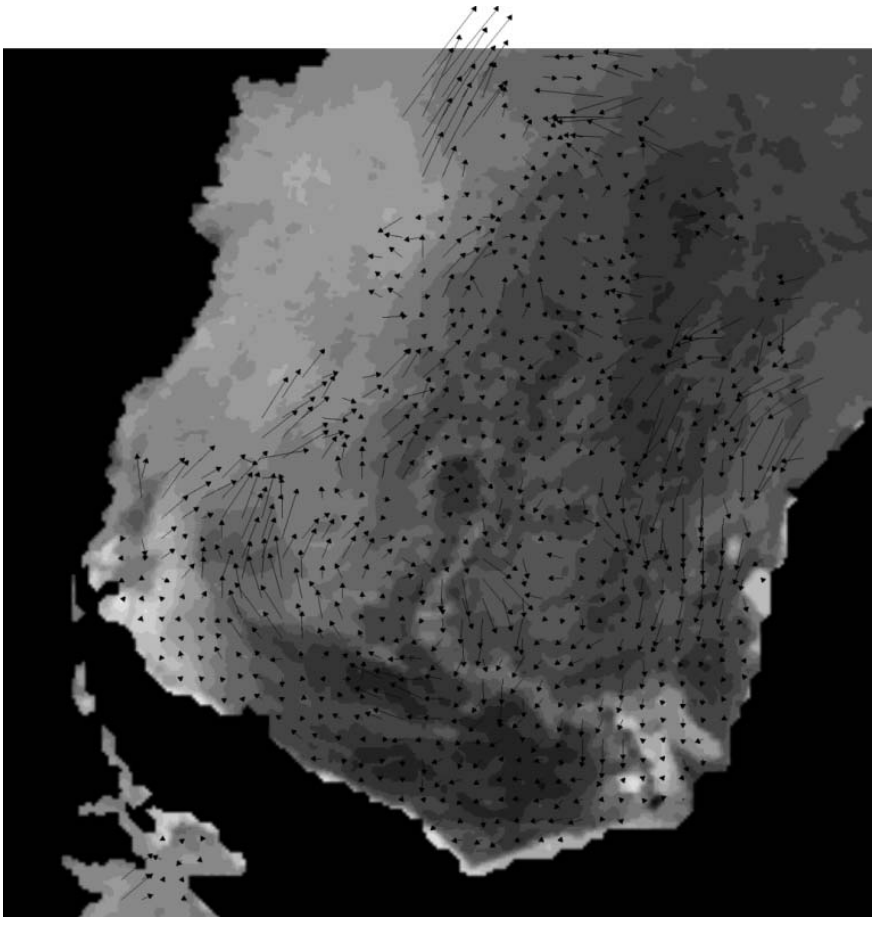

Fig. 8. NSCAT $\mathcal{A}_{V}$ image JD 271-276, 1996, with ice-motion vectors superimposed. Antarctic continent ice and open ocean are masked out. The Greenwich meridian forms the right vertical border while the lower boundary is the $90^{\circ} \mathrm{W}$ meridian in this polar stereographic projection.

and feature-tracking algorithms, originally designed and tuned for use in the Arctic, were developed to exploit the large microwave and radiometric contrast between multiyear and first year ice. Despite Antarctic sea ice exhibiting considerably different backscatter characteristics [13], [14], [16], [35], recent results indicate that Arctic ice tracking algorithms may be adjusted and applied to Antarctic SAR and AVHRR data with success [12], [19]. The following illustrate examples of sea ice tracking from NSCAT data in both hemispheres using contrasting approaches.

1) Antarctic Ice Tracking: Automated algorithms, originally used for tracking ice motion in high resolution $(100$ m) Antarctic SAR images [17]-[19], have been adapted for medium-scale, enhanced resolution scatterometer images. Correlations between features in "pairs" of six-day NSCAT images, separated by three-day intervals, are used to construct vector displacement charts. A Weddell Sea example of a gridded three-day mean ice velocity chart is shown in Fig. 8 for days 271-276, 1996. This polar stereographic representation indicates white ice-motion vectors superimposed on the NSCAT $\mathcal{A}_{V}$ image centered on day 273. The Antarctic continent ice is masked out and the Antarctic peninsula forms the black finger of land in the lower left corner of the image: the sea-ice margin runs along the left vertical border of the image. The Greenwich meridian forms the right vertical border of the image and the lower boundary is the $90^{\circ} \mathrm{W}$ meridian. The length and direction of the vectors in Fig. 8 indicate the scaled velocity in the given directions in polar stereographic coordinates. The motion vectors imply a clockwise cyclonic circulation pattern, with inflow at the eastern margin of the Weddell-Enderby Basin, along the coastline of Antarctica, and northward outflow along the Antarctic peninsula, along the lower boundary of the image. Sea-ice drift vectors turn abruptly eastward in the Antarctic circumpolar current as the ice approaches the marginal ice zone.

Results such as Fig. 8 indicate that the majority of the Antarctic ice may be tracked even during the period of austral 

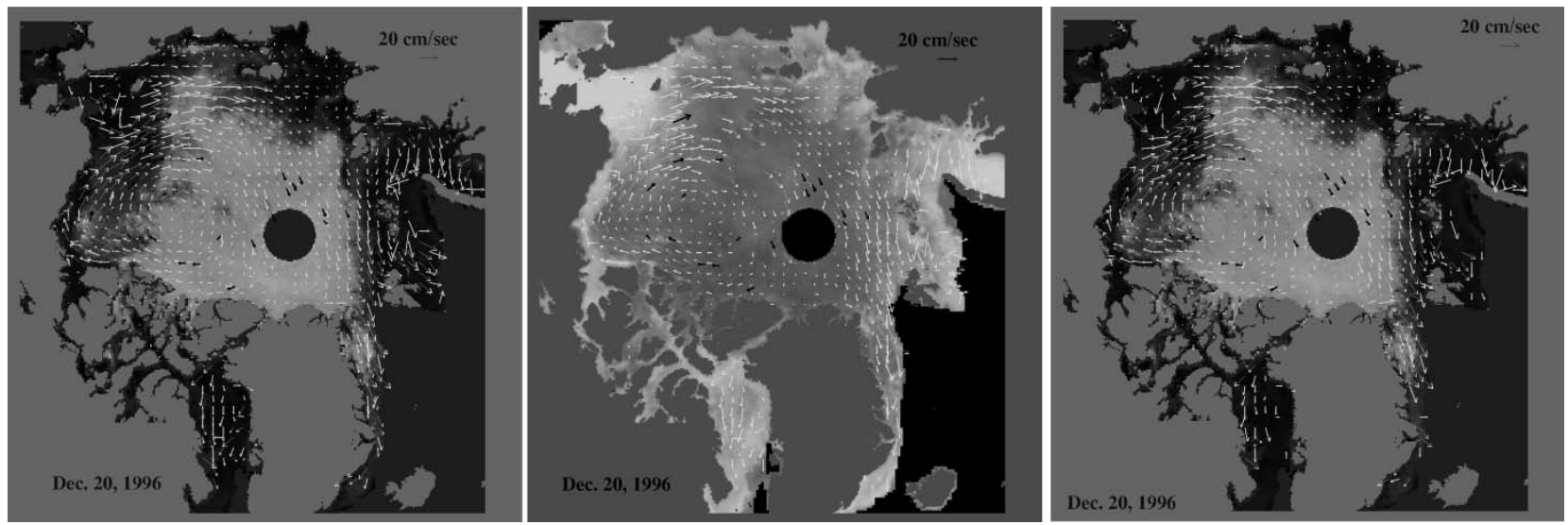

Fig. 9. Sea ice motion vectors derived from SSM/I (center panel) and NSCAT (right panel) data. Motion vectors overlay images from the respective sensors $\left(85 \mathrm{GHz} \mathrm{V}\right.$ for SSM/I, $\mathcal{A}_{V}$ for NSCAT). SSM/I- and NSCAT-derived motion vectors are in white while buoy motion vectors are in black. Note that the NSCAT and SSM/I-derived motions are consistent and complement each other. A merged motion map overlaying the NSCAT image is shown in the left panel [42], [43].

spring-summer melt onset, when ERS C-band scatterometer data suffer from snow-surface melting effects. Similarly, these Ku-band data offer an advantage over tracked $85 \mathrm{GHz} \mathrm{SSM} / \mathrm{I}$ passive microwave images because of more consistent vector retrievals during strong cyclonic activity. The only region of poor performance in Fig. 8 occurs in the bright sea-ice margin in the upper central part of the image. This region corresponds with brash ice and wave-fractured floes and has image characteristics making automatic tracking difficult.

2) Arctic Ice Tracking: Wavelet analysis of NSCAT data can be used to obtain daily sea ice drift information for both the northern and southern polar regions. Wavelet transforms, while analogous to Fourier transforms, are localized both in frequency and time. Recent investigations in physical oceanography have demonstrated the efficiency and utility of wavelet transforms to analyze nonlinear dynamical ocean systems. For example, a two-dimensional Gaussian wavelet (often referred to as a "Mexican-hat") transform has been applied to satellite images (SAR, AVHRR, and ocean color) to separate various scale processes including relative phase/location information for coastal watch applications [40] and for ice edge and ice floe tracking [41]. Wavelet transforms of satellite images can be used for near real-time "quick look" analyses of satellite data for feature detection, for data reduction using a binary image, and image enhancement by edge linking. Using wavelet transform techniques with sequential imagery from SSM/I and NSCAT data can provide ice motion observations [42], [43].

For application to NSCAT data, daily $\mathcal{A}_{V}$ images are constructed and the Mexican-hat wavelet transform is computed. Template matching is then performed with the wavelet transform of an earlier image. A four-day sliding window is used. Once the templates have been matched, the mean velocity vector is easily estimated by dividing the relative displacement over the image time interval of four days. Several different scales are used with the resultant motion vectors block averaged over a $100 \mathrm{~km} \times 100 \mathrm{~km}$ grid with outlier filtering. Fig. 9 shows the Arctic sea-ice drift derived from NSCAT data on December 20, 1996. White arrows indicate velocities derived from feature tracking using wavelet analysis, while red arrows indicate velocities from Arctic Ocean buoys.
Notice that the ice motion in Fram Strait/Baffin Bay and Greenland coast, and the major circulation in the central Arctic can be clearly identified. The empty areas in the map indicate the regions without ice tracking data due to the lack of suitable template matching in these areas. For comparison, similarly derived sea ice drift results from 85$\mathrm{GHz} \mathrm{SSM} / \mathrm{I}$ data are presented in Fig. 9. Since NSCAT is an active sensor which is not affected by cloud cover while $\mathrm{SSM} / \mathrm{I}$ can be, the consistency and agreement between SSM/I and NSCAT increases our confidence on the derived sea-ice drift results. We note that the regions with no ice-tracking data from NSCAT and SSM/I are generally not collocated since they result from physically different causes: surface roughness and brightness-temperature anomalies, respectively. Thus, the NSCAT and SSM/I results complement each other.

Arctic ocean buoys provide ground truth to evaluate the accuracy of the satellite-derived sea ice motion. Comparisons with ice motion derived from ocean buoys give good quantitative agreement. Both comparison results from NSCAT and SSM/I are compatible, and the results from NSCAT and $\mathrm{SSM} / \mathrm{I}$ complement each other. Combining the sea-ice drift daily results from NSCAT, SSM/I, and buoy data results in a merged composite map (see Fig. 9). These calibrated/validated results [42], [43] indicate that NSCAT, SSM/I merged daily ice motion are suitably accurate to identify large-scale sea ice dynamics and to improve our current knowledge of sea ice drift and related processes through the data assimilation in ocean-ice numerical models. Once the ocean-ice models are calibrated with the sea-ice drift derived from satellite data, open-water and new-ice production, ice thickness, and heat flux can be estimated with a higher accuracy and confidence [63].

\section{Sea Ice Classification}

Recent work to characterize sea-ice types using scatterometer data has demonstrated that the backscatter at $40^{\circ}$ incidence is particularly sensitive to the large-scale deformation or surface roughness and physical characteristics of the sea ice [13], [20], [31]. Furthermore, synoptic-scale NSCAT images can be exploited in conjunction with the ice dynamics infor- 

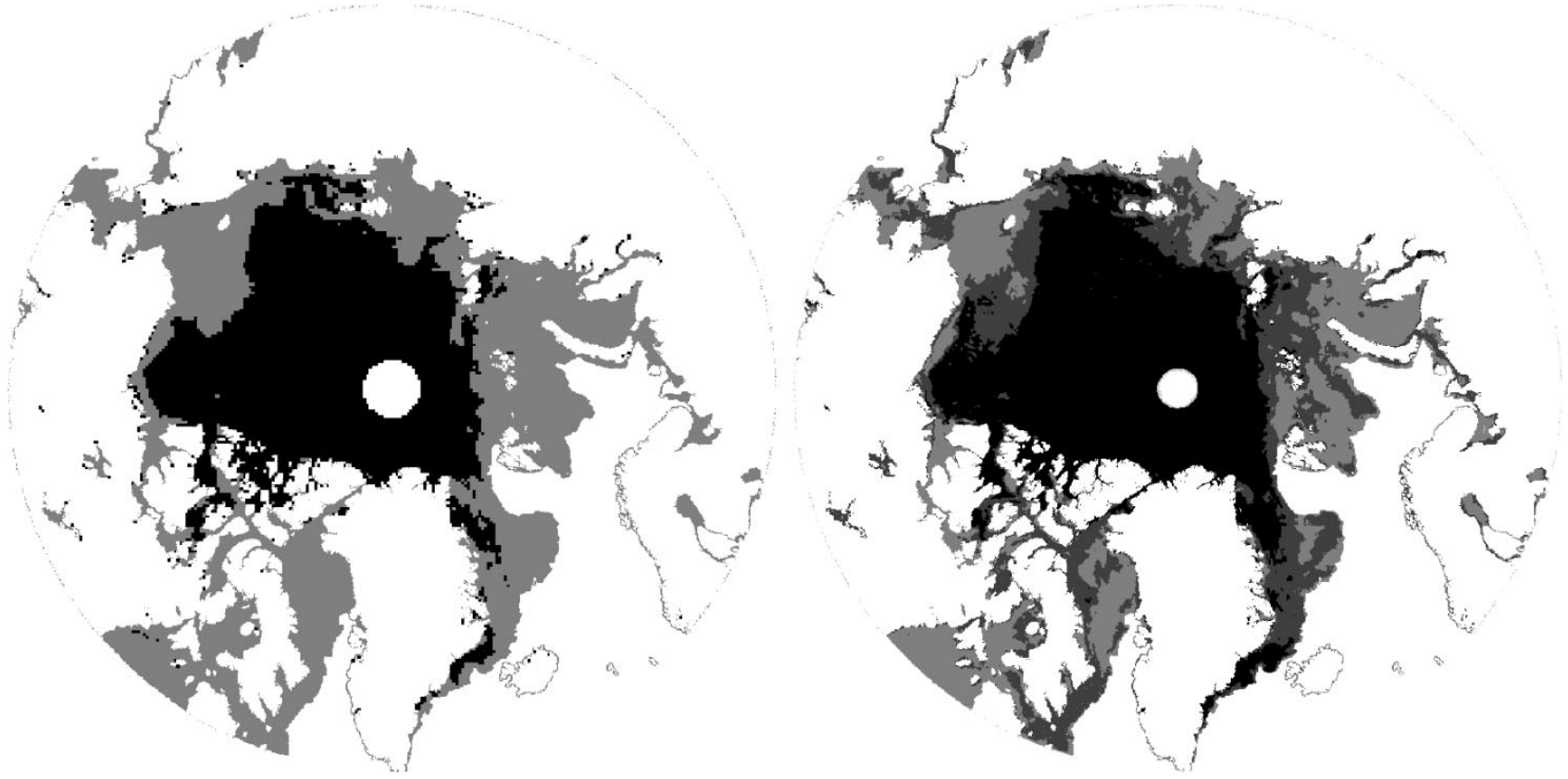

Fig. 10. Classified Arctic image data derived from (right) NSCAT SIRF data for days 4-9, 1997, using the $k$-means classifier; and (left) NASA Team algorithm SSM/I ice concentration where MY ice is set at ice concentrations exceeding $36 \%$. In the NSCAT image MY is black, RFY-like ice is medium gray, and SFY-like ice is light gray. Nilas-like ice does not appear at the printed resolution. In SSM/I image, MY is black and other ice is medium gray.

mation provided in the previous section to address global ice classification issues.

Drinkwater [12] has compared in situ measurements of ice characteristics with shipborne radar, SAR, and scatterometer backscatter signatures to confirm the appearance of four broad ice categories in the sea ice. These are: perennial or multiyear (MY), deformed or rough first year (RFY), smooth first year (SFY), and nilas ice. Each ice type has been found to exhibit characteristic scattering signatures in the four NSCAT parameters [52]. Several factors influence these signatures: surface roughness, salinity (dielectric properties), snow cover, and the distribution of inhomogeneities such as brine pockets and gas bubbles [35], [65], [71].

Multiyear ice typically has a very deformed surface with low salinity and low absorptive loss. Volume scattering is characteristic of MY ice as well as rough surface scattering. Consequently, the $\mathcal{A}$ values for multiyear ice are high $(\sim-5$ $\mathrm{dB}$ ) while the $\mathcal{B}$ values are also high (i.e., low gradient of $\sim-0.15$ ). Rough first year ice is well deformed ice, with an extremely rough surface ice due to ridging of the ice cover. High salinity and loss causes the dominant scattering mechanism to be the rough surface, rather than volume scattering. As a result, medium to high $\mathcal{A}$ and $\mathcal{B}$ values $(\mathcal{A} \sim-14 \mathrm{~dB}$ : $\mathcal{B} \sim-0.195)$ are generally observed. Smooth first year ice is characterized as undeformed, level ice with typical thicknesses greater than about $50 \mathrm{~cm}$. The high salinity and loss yield medium to low $\mathcal{A}$ values and low $\mathcal{B}$ values $(\mathcal{A} \sim-16.75$ $\mathrm{dB}: \mathcal{B} \sim-0.24$ ). Nilas is thin, smooth ice (typically $<10 \mathrm{~cm}$ ) forming under calm conditions usually in polynyas or open leads. It generally has a short life span due to the deformation induced by wave action and ridging and is rarely expansive on timescales of a few days or more. This ice type has very low $\mathcal{A}$ and $\mathcal{B}$ values $(\mathcal{A}<-20 \mathrm{~dB}: \mathcal{B}<-0.25)$.
Remund et al. [52] develop a four-dimensional feature classification using a $k$-means clustering approach to maximum likelihood classification with enhanced resolution $\mathcal{A}$ and $\mathcal{B}$ images. A preliminary result of the application of $k$-means to Arctic NSCAT SIRF image data are shown in Fig. 10. While no surface information is available to confirm the RFY, SFY, and nilas classes, the MY location in the NSCAT image can be compared with the NSIDC SSM/I-derived MY ice concentration images. In the SSM/I image, the average NSIDC MY ice concentration for 1997 JD 4-9 has been thresholded at $36 \%$. Clearly, there is a high correlation in the location of NSIDC 36\% MY ice and the NSCAT MY ice estimate.

Fig. 10 demonstrates that NSCAT data can have direct application to the classification of sea ice, and when combined with passive microwave and ERS-1/2 scatterometer SIRF images, are expected to enable a multispectral approach to unambiguous separation of broad sea-ice types.

\section{Glacial ICE}

First in 1978, and then continuously since 1991, microwave radar-equipped platforms have been used to understand the relationships between the physical properties of ice sheet surfaces and their backscatter characteristics at various frequencies, polarizations, and incidence angles [22], [26], [37], [59], [60]. Long and Drinkwater [45] have demonstrated with SASS data that Ku-band scatterometer images can be used to map the relative size and locations of ice sheet snow and ice physical zones or "facies" based on their scattering signatures. Backscattering of microwave signals from the surface depends on the roughness and electrical properties which, in turn, depend on the physical characteristics of the snow and ice cover [36], [58]. For example, liquid water in snow dramatically changes its permittivity and thus its 


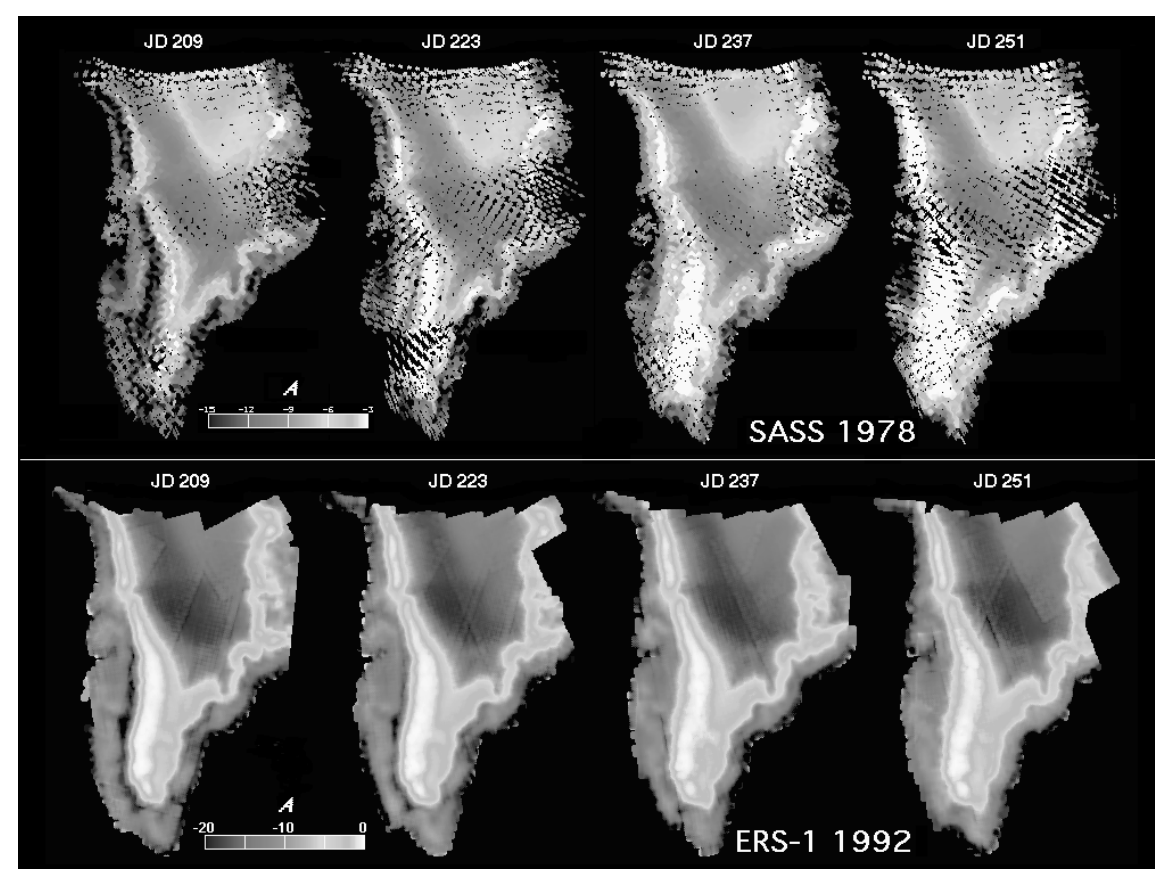

Fig. 11. Greenland SIRF $\mathcal{A}$ image time series from $1978 \mathrm{Ku}$-band SASS data and $1992 \mathrm{C}$-band ERS-1 data for the four periods spanning the period from summer melt through freeze-up. The imaging period is two weeks.

microwave scattering signature. This provides an efficient means of monitoring changes which result from melting and snow metamorphosis.

Currently, satellite synthetic aperture radar (SAR) provides high resolution, $100 \times 100 \mathrm{~km}$ scenes, but their spatiotemporal coverage of ice sheets is limited. Radar mosaics can be produced [28]; however, terrain-corrected digitally mosaiced images take a long time both to acquire and to create. They also do not accurately represent widespread conditions over a sufficiently short period of time to be able to monitor the large-scale, rapid backscatter variability accompanying seasonal change. NSCAT and other scatterometers, in contrast, provide more frequent coverage, albeit at lower resolution. Measurements of the radar backscatter coefficient over a broad range of incidence angles allows the scattering mechanism to be more readily determined.

\section{A. The Greenland Ice Sheet}

The Greenland ice sheet is conveniently divided into zones or "facies" within which near-surface snow, firn, and ice properties have unique characteristics [3]. Boundaries between facies are established with respect to the timing and expression of maximum melt conditions. At the lowest elevations, summer melting removes the entire annual accumulation of snow to expose glacial ice. The firn line delimits the upper margin of this zone, delineating it from the region in which complete saturation of the remaining snow layer occurs (i.e., "soaked" facies). The upper limit of soaking is called the saturation line. Localized melt-water percolation occurs between this and the highest elevation limit of surface melt marked by the dry snow line. In the percolation facies, the annual accumulation of snow is neither completely wetted nor raised to the melting point.
Melting and percolation decreases with elevation, diminishing to a negligible amount at the lower boundary of the dry snow zone.

A variety of studies have concluded that visible wavelength satellite data are inappropriate for monitoring changes in ice sheet facies in response to climate change, as boundaries are not consistently expressed as strong gradients in optical properties [67] of the uppermost snow and firn. Thus glacier facies are best discerned with measurements penetrating several meters into the surface of the snow and ice. Microwaves are suited for such observations since they are particularly sensitive to variations in both surface and subsurface characteristics [36], [45], [58], [64].

1) Seasonal Variability: The untimely end of the NSCAT mission limits our ability to use NSCAT data to study melt events in Greenland. However, important insights about the utility of scatterometer data can be gleaned from a combination of data from SASS, NSCAT, and the ERS- $1 / 2$ scatterometers (ESCAT). Seasonal modulations of $\sigma^{\circ}$ in $1978 \mathrm{Ku}$-band SASS and 1992 C-band data in Fig. 11 demonstrate the sensitivity of $\mathrm{Ku}$ - and $\mathrm{C}$-band $\mathcal{A}$ values to spatio-temporal changes in surface and subsurface properties. During summer, the principal parameter affecting the microwave response of the ice sheet is the appearance of snow liquid water in areas experiencing surface melt. During winter, $\sigma^{\circ}$ is primarily affected by layering [59], [60] and inhomogeneities developing as a consequence of seasonal accumulation and melt patterns. Changes in the surface reflectivity caused by melting result in reductions in $\sigma^{\circ}$ exceeding $15 \mathrm{~dB}$ [45]. In Fig. 11 the extent of summer melt is delineated by extremely low $\sigma^{\circ}$ values (black), particularly on day 209. As the response to surface melt is similar at C- and Ku-band, differences in melt extent between 


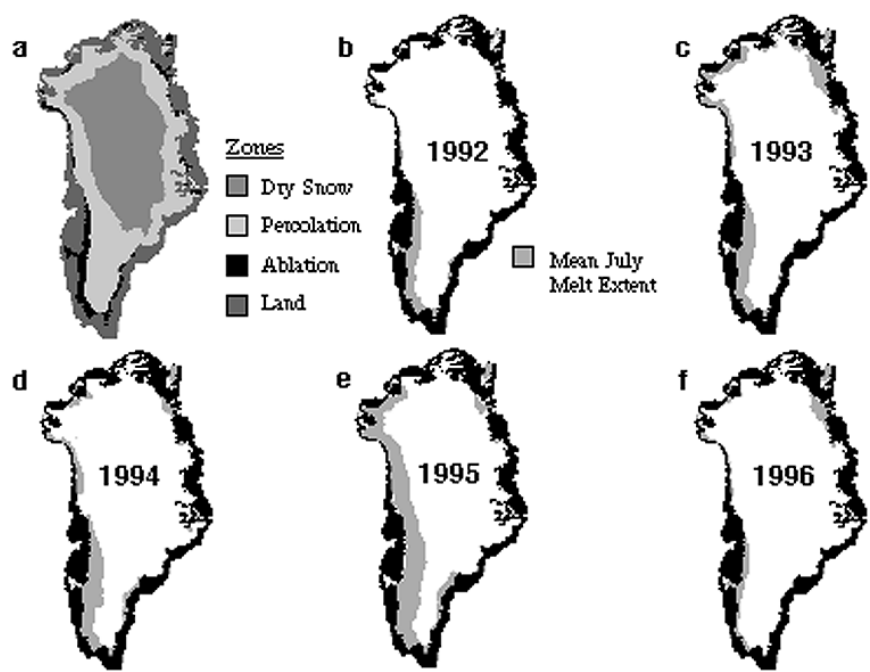

Fig. 12. (a) Greenland snow and ice facies determined from 1996 ESCAT and NSCAT data; and (b)-(f) mean monthly ice sheet melt extent, determined from ESCAT scatterometer images from 1992 to 1996.

SASS and ESCAT are accounted for by interannual variability in the length and extent of the seasonal melting. Typically, melting ceases by late August (day 237), and refreezing of the firn increases $\sigma^{\mathrm{C}}$ at both frequencies.

In Fig. 12, pixels experiencing melt are mapped using summer C-band ESCAT $\mathcal{A}$ images from 1992 to 1997 via an algorithm which tracks melting as a function of the sharp reduction in backscatter. Monthly average images of July melt extent are shown together with a 1996 map [Fig. 12(a)] indicating the primary snow and ice zones recovered in conjunction with Ku-band NSCAT data. In comparisons with passive microwave time series in [1], Fig. 12 suggests that the Greenland ice sheet experienced two of the smallest (1992: $8.1 \times 10^{4} \mathrm{~km}^{2}$; and 1996: $10.4 \times 10^{4} \mathrm{~km}^{2}$ ), and perhaps the largest $\left(1995: 25 \times 10^{4} \mathrm{~km}^{2}\right)$ melt events in the last two decades. In 1995, melting encroaches upslope upon the dry snow zone along the entire northwestern flank of the ice sheet.

During summer in the percolation zone, prominent stratigraphic discontinuities form as meltwater percolates downward and refreezes at depth $(\sim 1 \mathrm{~m})$ in relatively colder snow [3]. Typically, a distinct horizon forms comprising a high proportion of solid ice in layers, lenses, and ice pipes. The lower percolation zone boundary is indicated in Fig. 11 by the sharp transition from low to extremely high $\mathcal{A}$ values. As the surface layer cools and the penetration depth increases beyond the depth at which ice lenses formed, the resultant volume scattering from buried inhomogeneities increases to the highest intensity backscatter on earth, in both $\mathrm{Ku}-$ and C-band images [36], [58]. This characteristic of the dual-frequency backscattering was used to derive the lower boundary in the snow facies map in Fig. 12(a).

Above the "dry snow line," the dry snow zone experiences negligible variability in $\mathcal{A}$ values, since by definition it experiences little or no surface melting during summer. After autumnal cooling, a sharp spatial gradient in backscatter delimits the dry snow zone from the percolation zone. In
Fig. 11, low backscatter returns at high altitude (in central Greenland) are well delineated from percolation zone $\mathcal{A}$ values exceeding $-5 \mathrm{~dB}$ at Ku-band. In dry snow, C-band microwaves penetrate somewhat more effectively than Ku-band with relatively smaller absorption scattering and absorption losses. At Ku-band, microwaves are more effectively scattered, particularly by the snow grains themselves, thereby resulting in larger $\mathrm{Ku}$-band $\mathcal{A}$ values in the dry snow zone.

2) Long Term Change: The real potential of a commitment to consecutive scatterometer missions is the likelihood of obtaining repeat image data which can be employed in detecting long-term changes in the large ice sheets. The acquisition of NSCAT data over the Greenland ice sheet, during at least part of the same season as Seasat, enables longterm (18-year) change maps to be derived, by calculating the difference in $\sigma^{\circ}$ (i.e., NSCAT-SASS) between seasonal mean images from the period after autumnal cooling. Fig. 13(a) shows a VV-polarized NSCAT image for the period between day 267 and 272 (September 24-29) in 1996. Alongside in Fig. 13(b) is the result of combining and median filtering the sparse measurements obtained by SASS between days 250 and 283 (September 6-October 9) in 1978. The result in each case is a seasonal average image for the period following the autumnal freeze-up. Fig. 13(b) is essentially similar in image characteristics for the same period in Fig. 11(d). Subtle differences between the NSCAT and Seasat SASS $\mathcal{A}$ images are evident in Fig. 13(c), with differences highlighted for the range $\pm 3 \mathrm{~dB}$. Surfaces experiencing extreme change are noted as either dark or light tones. Black indicates a reduction in backscatter of $-3 \mathrm{~dB}$ or more over the 18-year period, while light tones show regions with $>3 \mathrm{~dB}$ of increase.

The Ku-band $\mathcal{A}$ difference image in Fig. 13(c) is the difference between two seasonal snapshot images and contains a record of the zones of greatest variability in $\sigma^{\mathrm{c}}$ over the intervening 18-year period, through the impact of snow stratigraphy changes. Patterns in Fig. 13(c) indicate a spatial pattern highly correlated with the snow and ice facies identified by Benson [3]. Fig. 13(c) essentially illustrates the areas of primary interannual variability within each of the snow and ice facies. It indicates that the melt line (the lower boundary of dry snow zone) has an extremely large interannual variability, not previously identified in radar data. Fig. 12 confirms large changes in the mean melt area, but the July monthly mean does not capture the maximum extent of melting often only experienced within a narrow range of dates. Normally this occurs around mid July with typical interannual variability of several days in the timing of peak melt.

The $\mathcal{A}$ difference image in Fig. 13(c) contains microwave archaeological radar evidence for previous melting within the dry snow zone, through the influence of buried scatterers beneath the most recent year's annual snow accumulation. Evidence confirms an upslope migration of the upper boundary of the percolation zone. From Fig. 11(e) and evidence in Fig. 12(c), July 1995 was the period of maximum melt extent within the last two decades. This conclusion is made because NSCAT penetrates sufficiently deeply to sense percolation inhomogeneities produced in the summer of 1995 along the lower elevation fringes of the dry-snow zone. A further 


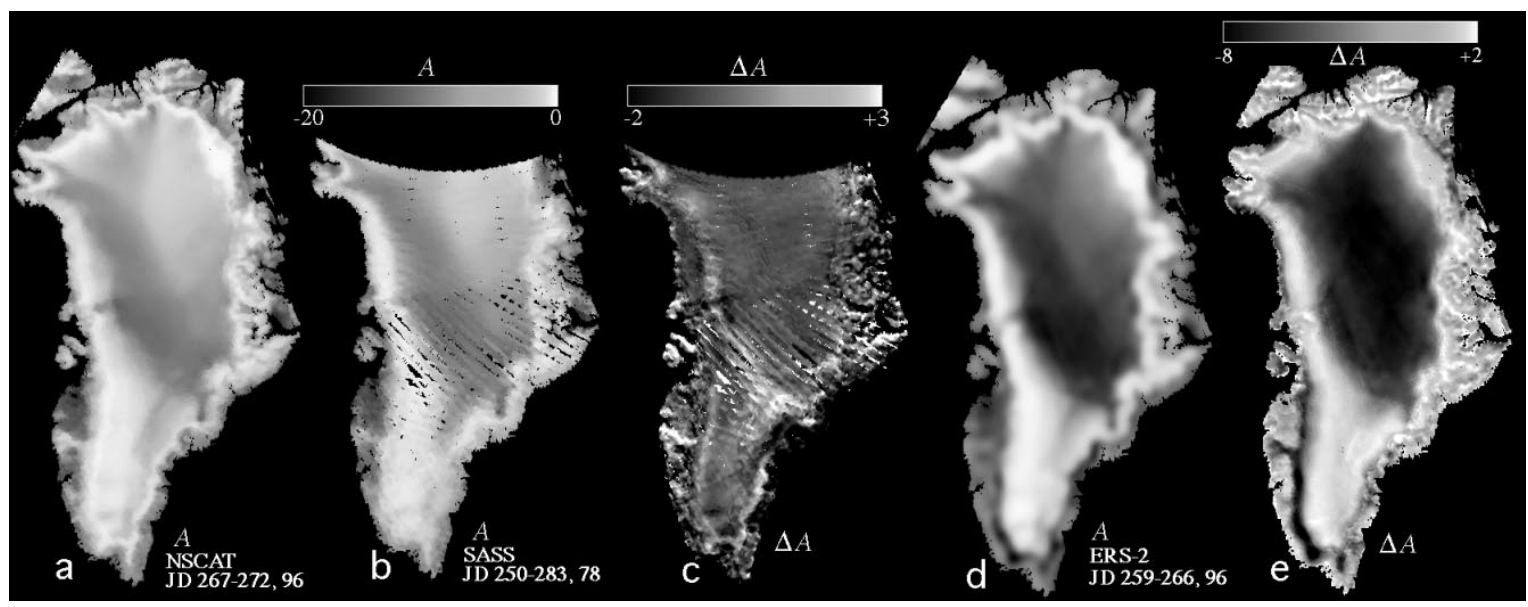

Fig. 13. (a) NSCAT $\mathcal{A}$ image for the period 267-272, 1996; (b) SASS $\mathcal{A}$ image for days 250-283, 1978; (c) NSCAT-SASS $\mathcal{A}$ difference map of Greenland. (d) ERS-2 $\mathcal{A}$ image for days 267-272, 1996; and (e) ERS-NSCAT (C-Ku band) $\mathcal{A}$ difference image for days 267-272.

intersatellite difference image $(\Delta \mathcal{A}=$ NSCAT-ESCAT $)$ in Fig. 13(d) corroborates these changes. It shows the difference in $\sigma^{\circ}$ between the Ku- and C-band $\mathcal{A}$ images in Fig. 13(a) and (d) and highlights zones of wavelength-dependent volume scattering intensity. As dry snow has a lower $\sigma^{\circ}$ at C-band, due to the primary backscattering occurring from Rayleigh scattering from snow grains (in the absence of strong stratigraphy), the dry-snow zone produces large positive values in Fig. 13(e). A contrast reversal occurs in the zone influenced by percolation, due to ESCAT penetrating deeper and responding more sensitively to buried ice lenses than NSCAT. This results in negative values in the percolation zone.

\section{B. Antarctic Ice Shelves/Larsen Ice Shelf}

Evidence of warming in the vicinity of the Antarctic peninsula over the last decade has raised concerns about the stability of the large ice shelves in that region, especially in light of recent calvings resulting in the disintegration of the Wordie Ice Shelf [11] and the Larsen Ice Shelf [61], [62]. Seasonal transitions in NSCAT backscatter, illustrated by the images in Fig. 14, and backscatter and radiometric time-series data provided by NSCAT in conjunction with ESCAT and SSM/I, in Fig. 15, together illustrate the value of consistent longterm, uninterrupted measurements of such delicate regions for monitoring the impact of interannual melt fluctuations on the stability of the ice shelves. Fig. 14 shows the progression in austral summer melt on the Larsen ice shelf, clearly visible as modulations in $\mathcal{A}$ values. Spatial variations in the air temperatures result in variations in surface reflectivity and melt conditions result in the lowest $\mathcal{A}$ values. At JD 352-357, a distinct melt front is visible during the southward progression in snow surface melting. By JD 17-21, the entire Larsen ice shelf is melting, and the extent of the ice shelf is clearly delineated by the low backscatter values.

Fig. 15 confirms significant interannual variability of the melting over the last several years. SSM/I brightness temperatures tend abruptly to blackbody temperatures during periods of summer melting $(273 \mathrm{~K})$, and subsequently cooling more slowly with the onset of winter. Values of $\mathcal{A}_{V}$ from NSCAT and ESCAT follow in anticorrelation, rapidly falling with the onset of summer melt and slowly rising again to values approaching $0 \mathrm{~dB}$ throughout the winter months. These data indicate that melting during the summers of $1992 / 1993$ and 1994/1995 were extensive both in time and space on the ice shelves fringing the Antarctic peninsula. In contrast, the 1993/1994 summer was less intense. The more recent overlapping NSCAT time series indicates that 1996/1997 was also particularly intense, and it is suggested that such protracted periods of melting perhaps contributed to weakening of the ice shelf and thus the large iceberg calvings occurring in those years [61], [62]. Local foehn winds observed on the eastern side of the barrier imposed by the mountain chain also result in extreme spatial temperature gradients. Clearly, warming occurring over the last 30 years is having a significant impact on the distribution of melting on the large ice shelves in this region, and future QuikScat and Seawinds images will be used for charting the regional distribution of seasonal melting both on the floating ice shelves and the periphery of the continental ice sheet.

\section{DISCUSSION}

NSCAT has proved its unique capability for extracting information on polar ice characteristics and it is clear that scatterometry has an extremely important role to play in the study of the cryosphere. In particular, the combination of C-band and Ku-band scatterometry with SSM/I will provide complementary data sets. Time series data such as for Greenland and the Larsen Ice Shelf and other regions of extreme climate sensitivity demonstrate a clear requirement for continued long-term consistent monitoring with scatterometers. NSCAT provided an independent data source which complements the existing C-band scatterometer record and the long-term SSM/I and SMMR climatological data sets. The launches of QuikScat and Seawinds will extend the Ku-band data set and strengthen our capabilities for extracting polar snow and ice characteristics and monitoring climate change impact. Although the QuikScat and Seawinds scatterometers differ in design from NSCAT, NSCAT algorithms and analysis techniques can be extended to these sensors, e.g., [53]. 


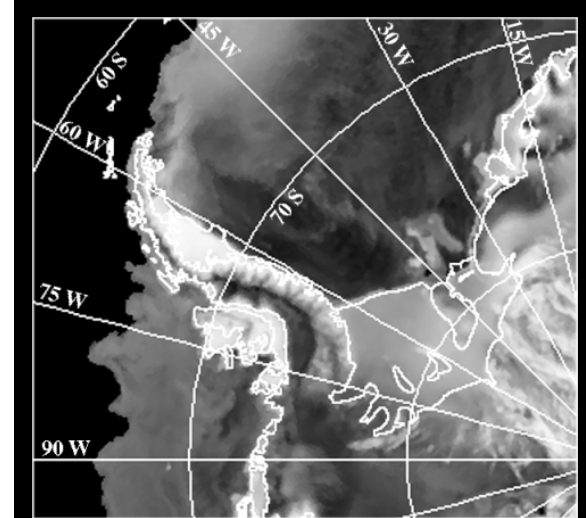

96 JD 277-282

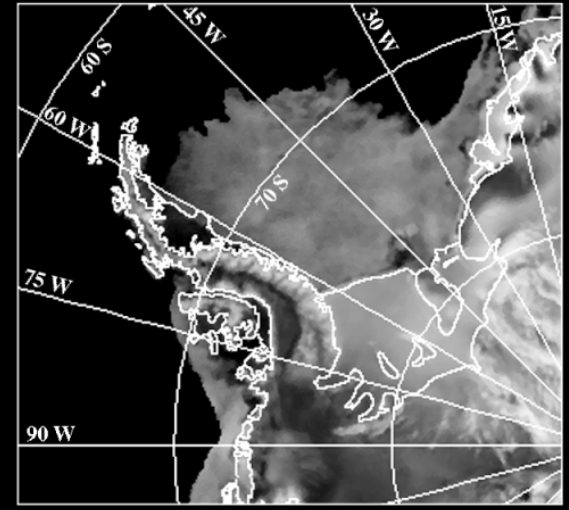

97 JD 17-21

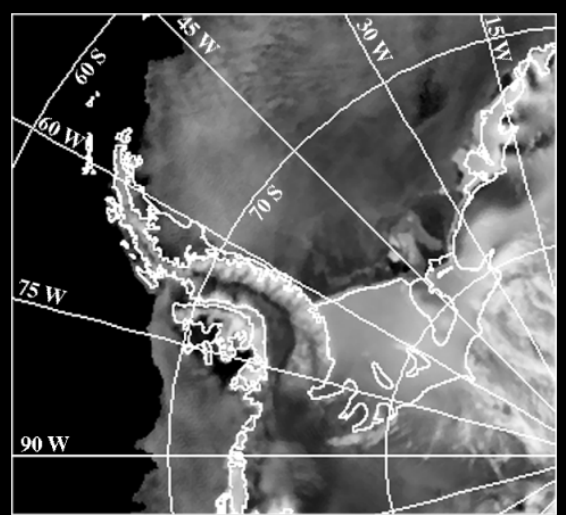

96 JD 346-351

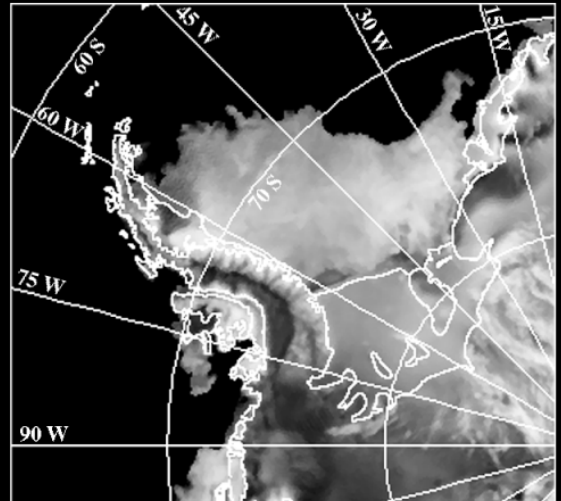

97 JD $43-48$

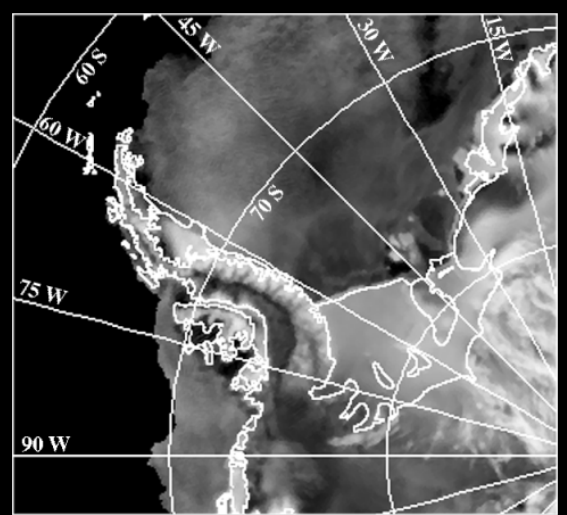

96 JD 352-357

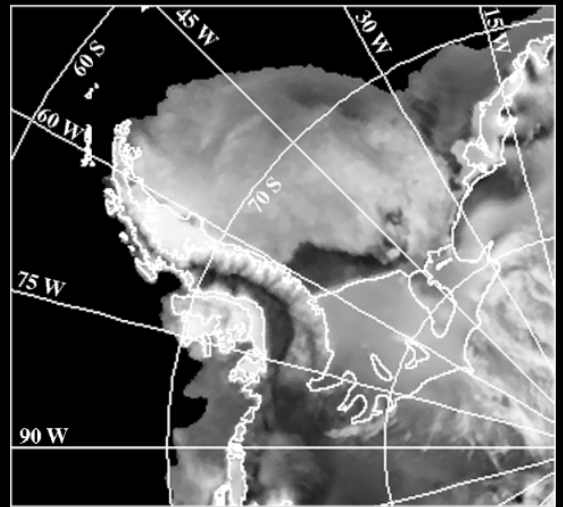

97 JD 88-93

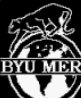

$\begin{array}{rll}-20 & A(d B) & 0\end{array}$

Fig. 14. Larsen Ice Shelf NSCAT $\mathcal{A}$ time series showing variability in ice shelf conditions and the progression in the extent of summer melting.

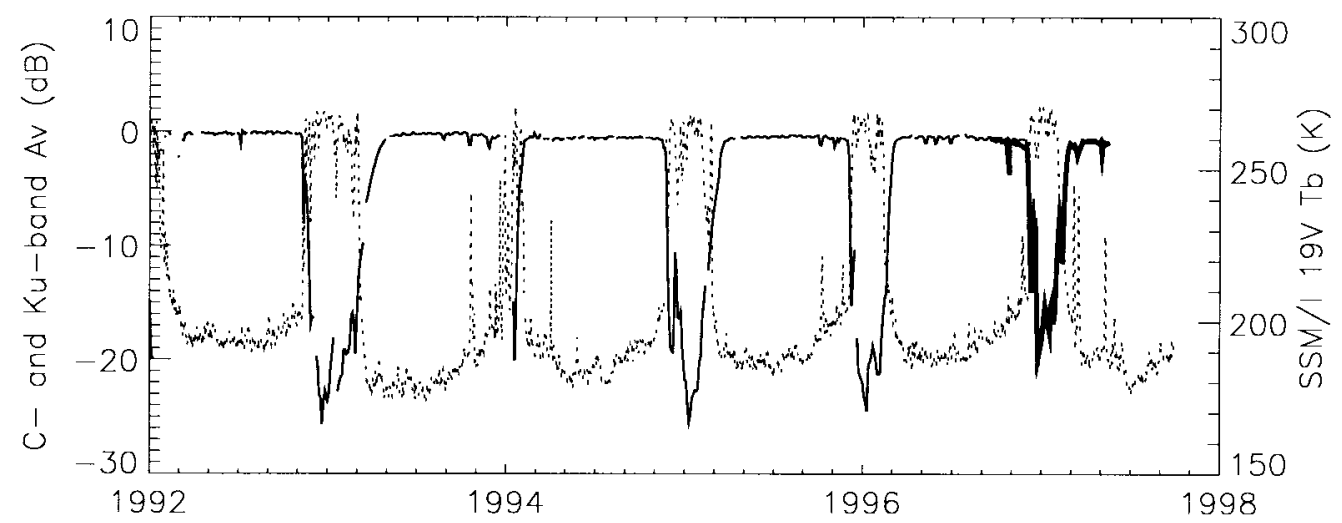

Fig. 15. Interannual variability in the Larsen Ice Shelf observed by NSCAT, ERS-1/2, and SSM/I, with Ku-band $\mathcal{A}_{V}$ (thick line), C-band $\mathcal{A}_{V}$ (thin line), and $19 \mathrm{GHz}$ brightness temperature (dashed line), respectively.

\section{ACKNOWLEDGMENT}

The authors wish to thank A. Liu for generating the Arctic ice motion images and R. Kwok for the Weddell Sea ice motion figure. They also wish to thank Q. Remund for his help in preparing images. NSCAT data was obtained from the PO.DAAC at the Jet Propulsion Laboratory, Pasadena, CA. $\mathrm{SSM} / \mathrm{I}$ data was obtained from the National Sea Ice Data Center (NSIDC).

\section{REFERENCES}

[1] W. Abdelati and K. Steffen, "Snowmelt on the Greenland ice sheet as derived from passive microwave satellite data," J. Climate, vol. 10, no. 2, pp. 165-175, 1997

[2] S. G. Beavan and S. P. Gogineni, "Fusion of satellite SAR with passive microwave data for sea ice remote sensing," in Analysis of SAR Data of the Polar Oceans, C. Tsatsoulis and R. Kwok, Eds. Berlin, Germany: Springer-Verlag, 1998, ch. 8, pp. 91-109.

[3] C. S. Benson, "Stratigraphic studies in the snow and firn of the Greenland ice sheet," SIPRE Res. Rep., no. 70, 1962. 
[4] R. Bindshadler, "Monitoring ice sheet behavior from space," Rev. Geophys., vol. 36, no. 1, pp. 79-104, 1998

[5] M. A. Bourassa, M. H. Freilich, D. M. Legler, W. T. Liu, and J. J. O'Brien, "Wind observations from new satellite and research vessels agree," EOS Trans. Amer. Geophys. Union, vol. 78, pp. 597 \& 602, 1997.

[6] W. F. Budd, "Antarctic sea ice variations from satellite sensing in relation to climate," IEEE Trans. Geosci. Remote Sensing, vol. GE-15, pp. 417-426, 1975.

[7] F. D. Carsey, "Summer arctic sea ice character from satellite microwave data," J. Geophys. Res., vol. 90, no. C3, pp. 5015-5034, 1985.

[8] D. J. Cavalieri, J. P. Crawford, M. R. Drinkwater, D. T. Eppler, L. D. Farmer, R. R. Jentz, and E. C. Wackerman, "Aircraft active and passive microwave validation of sea ice concentration from the defense meteorological satellite program special sensor microwave imager," $J$. Geophys. Res., vol. 96, no. C12, pp. 21 989-22 008, 1991.

[9] D. J. Cavalieri, P. Gloersen, and W. J. Campbell, "Determination of sea ice parameters with the Nimbus-7 SMMR," J. Geophys. Res., vol. 89, no. D4, pp. 5355-5369, 1984

[10] W. L. Chapman and J. E. Walsh, "Recent variations of sea ice and air temperature in high latitudes," Bull. Amer. Meteorol. Soc., vol. 74, no. 1, pp. 33-47, 1993.

[11] C. S. M. Doake and D. G. Vaughan, "Rapid disintegration of the Wordie ice shelf in response to atmospheric warming," Nature, vol. 350, p. 328, 1991.

[12] M. R. Drinkwater, "Active microwave remote sensing observations of Weddell sea ice," in Antarctic Sea Ice Physical Processes, Interactions and Variability, Antarct. Res. Ser., M. O. Jeffries, Ed. Washington, DC: AGU, 1998, vol. 74, pp. 187-212.

[13] _ "Satellite microwave radar observation of Antarctic sea ice," in Recent Advances in the Analysis of SAR for Studies in the Polar Oceans, C. Tsatsoulis and R. Kwok, Eds. Berlin, Germany: Springer-Verlag, 1998, chap. 8, pp. 145-182.

[14] M. R. Drinkwater, X. Liu, and D. Low, "Interannual variability in Weddell sea ice from ERS wind scatterometer," in Proc. IGARSS'98, Seattle, WA, July 6-10, 1998, pp. 1982-1984.

[15] M. R. Drinkwater and D. G. Long, "Seasat, ERS-1/2 and NSCAT scatterometer observed changes on the large ice sheets," in Proc. IGARSS'98, Seattle, WA, July 6-10, 1998, pp. 2252-2254.

[16] M. R. Drinkwater and V. I. Lytle, "ERS-1 radar and field-observed characteristics of autumn freeze-up in the Weddell Sea," J. Geophys. Res., vol. 102, no. C6, pp. 12 593-12 608, 1997.

[17] M. R. Drinkwater, "Satellite microwave radar Observations of climaterelated sea-ice anomalies," in Bull. Amer. Meteorol. Soc., Proc. Workshop on Polar Processes in Global Climate, Nov. 13-15, 1996, pp. 115-118, 1997.

[18] M. R. Drinkwater and X. Liu, "Observing interannual variability in seaice dynamics using NSCAT," in Proc. NSCAT Science Team Workshop, Honolulu, HI, Jan. 23-24, 1997; JPL Tech. Publ., Jet Propulsion Laboratory, Pasadena, CA, 1997.

[19] M. R. Drinkwater and C. Kottmeier, "Satellite microwave radar- and buoy-tracked ice motion in the Weddell Sea during WWGS'92," in Proc. IGARSS'94, Pasadena, CA, Aug. 8-12, 1994, vol. 1, pp. 153-155.

[20] M. R. Drinkwater, D. G. Long, and D. S. Early, "Enhanced resolution ERS-1 scatterometer imaging of southern ocean sea ice," ESA J., vol 17, pp. 307-322, 1994

[21] M. R. Drinkwater and F. D. Carsey, "Observations of the late-summer to fall transition with the $14.6 \mathrm{GHz}$ SEASAT scatterometer," in Proc. IGARSS'91 Symp., Espoo, Finland, June 3-6, 1991, vol. 3, pp. $1597-1600$

[22] M. R. Drinkwater and J. A. Dowdeswell, "A multi-sensor approach to the interpretation of radar altimeter waveforms from two Arctic ice caps," Ann. Glaciology, vol. 9, pp. 60-68, 1987.

[23] D. S. Early and D. G. Long, "Azimuthal modulation of C-band scatterometer $\sigma^{\circ}$ over southern ocean sea ice," IEEE Trans. Geosci. Remote Sensing, vol. 35, pp. 1201-1209, Sept. 1997.

[24] "Scatterometer resolution enhancement," in Proc. IGARSS'98, Seattle, WA, July 6-10, 1998, pp. 1970-1972.

[25] _ "Enhanced resolution imaging from irregular samples," in Proc. IGARSS'97, Singapore, Aug. 4-8, 1997, pp. 1844-1846.

[26] C. Elachi and W. E. Brown, "Imaging and sounding of ice fields with airborne coherent radars," J. Geophys. Res., vol. 80, pp. 1113-1119, 1975.

[27] C. F. Emmett, R. R. Jensen, P. J. Hardin, and D. G. Long, "Detecting change in equatorial regions of Brazil using medium resolution satellite imagery," in Proc. IGARSS'97, Singapore, Aug. 4-8, 1997, pp. $1557-1559$.
[28] M. Fahnestock, R. Bindschadler, R. Kwok, and K. Jezek, "Greenland ice sheet surface properties and ice dynamics from ERS-1 SAR imagery," Science, vol. 262, pp. 1530-1534, 1993

[29] F. M. Fetterer, M. R. Drinkwater, K. C. Jezek, S. W. C. Laxon, R G. Onstott, and L. M. H. Ulander, "Sea ice altimetry," in Microwave Remote Sensing of Sea Ice, F. D. Carsey, Ed. Washington, DC: AGU, 1992, pp. 111-135.

[30] P. Gloersen, W. J. Campbell, D. J. Cavalieri, J. C. Comiso, C. L. Parkinson, and H. J. Zwally, Arctic and Antarctic Sea Ice, 1978-1987: Satellite Passive-Microwave Observations and Analysis, Scientific and Technical Information Program, National Aeronautics and Space Administration, Washington, D.C., 1992, p. 290

[31] F. Gohin and A. Cavanie, "A first try at identification of sea ice using the three beams of ERS-1," Int. J. Remote Sensing, vol. 15, pp. 1221-1228, 1994.

[32] M. Hallikainen and D. P. Winebrenner, "The physical basis for sea ice remote sensing," in Microwave Remote Sensing of Sea Ice, F. D. Carsey, Ed. American Geophysical Union, Geophysical Monograph 28, ch. 3, pp. 29-46, 1992

[33] P. J. Hardin and D. G. Long, "Integrating reconstructed scatterometer and advanced very high resolution radiometer data for tropical forest inventory," Opt. Eng., vol. 34, no. 11, pp. 3146-3153, Nov. 1995.

[34] B. Holt, D. A. Rothrock, and R. Kwok, "Determination of sea ice motion from satellite images," in Microwave Remote Sensing of Sea Ice, F. D. Carsey, Ed. American Geophysical Union, Geophysical Monograph 28 , ch. 18,1992 , pp. 343-353.

[35] A. R. Hosseinmostafa, V. I. Lytle, K. C. Jezek, S. P. Gogineni, S F. Ackley, and R. K. Moore, "Comparison of radar backscatter from antarctic and Arctic Sea ice," J. Electromagn. Waves Appl., vol. 9, no. 3, pp. 421-438, 1995

[36] K. C. Jezek, P. Gogineni, and M. Shanableh, "Radar measurements of zones on the Greenland ice sheet," Geophys. Res. Lett., vol. 21, no. 1, pp. 33-36, 1994.

[37] K. C. Jezek, M. R. Drinkwater, J. P. Crawford, and R. Kwok, "Analysis of synthetic aperture radar data collected over the southwestern Greenland ice sheet," J. Glaciol., vol. 39, no. 31, pp. 119-132, 1993.

[38] R. Kwok, J. C. Curlander, R. McConnell, and S. S. Pang, "An icemotion tracking system at the Alaska SAR Facility," IEEE J. Oceanic Eng., vol. 15, no. 1, pp. 44-54, 1990.

[39] P. Lecomte, A. Cavanie, and F. Gohin, "Recognition of sea ice zones using ERS-1 scatterometer data," in Proc. IGARSS'93, 1993, pp. 855-857.

[40] A. K. Liu, C. Y. Peng, and S. Y.-S. Chang, "Wavelet analysis of satellite images for coastal watch," IEEE J. Oceanic Eng., vol. 22, no. 1, pp. 9-17, 1997.

[41] A. K. Liu, S. Martin, and R. Kwok, "Tracking of ice edge and ice floes by wavelet analysis of SAR images," J. Atmos. Oceanic Technol., vol. 14, pp. 1187-1198, 1997.

[42] A. K. Liu and D. J. Cavalieri, "Sea-ice drift from wavelet analysis of DMSP SSM/I data," Int. J. Remote Sens., to be published.

[43] A. K. Liu, Y. Zhao, and W. T. Liu, "Sea ice motion derived from satellite agrees with buoy observations," EOS Trans., 1998.

[44] W. T. Liu, W. Tang, and P. S. Polito, "NASA scatterometer provides global ocean-surface wind fields with more structures than numerical weather prediction," Geophys. Res. Lett., vol. 25, no. 6, pp. 761-764, Mar. 1998.

[45] D. G. Long and M. Drinkwater, "Greenland ice-sheet surface properties observed by the Seasat-A scatterometer at enhanced resolution," $J$. Glaciology, vol. 40, no. 135, pp. 213-230, 1994.

[46] D. G. Long and P. J. Hardin, "Vegetation studies of the Amazon Basin using enhanced resolution Seasat scatterometer data," IEEE Trans. Geosci. Remote Sensing, vol. 32, pp. 449-460, Mar. 1994.

[47] D. G. Long, P. Hardin, and P. Whiting, "Resolution enhancement of spaceborne scatterometer data," IEEE Trans. Geosci. Remote Sensing, vol. 31, pp. 700-715, 1993.

[48] G. A. Maykut, "The surface heat and mass balance," in The Geophysics of Sea Ice, N. Untersteiner, Ed. New York: Plenum, 1985, pp. 395-463

[49] F. M. Naderi, M. H. Freilich, and D. G. Long, "Spaceborne radar measurement of wind velocity over the ocean-An overview of the NSCAT scatterometer system," Proc. IEEE, vol. 79, pp. 850-866, June 1991.

[50] C. L. Parkinson, "Spatial patterns in the length of sea-ice season in the Southern Ocean, 1979-1986," J. Geophys. Res., vol. 99, pp. $16327-16339,1994$

[51] C. Oelke, "Atmospheric signatures in sea-ice concentration estimates from passive microwaves: Modeled and observed," Int. J. Remote Sens., vol. 18 , no. 5 , pp. 1113-1136, 1997. 
[52] Q. P. Remund, D. G. Long, and M. R. Drinkwater, "Polar sea ice classification using enhanced resolution NSCAT data," in Proc. IGARSS'98, Seattle, WA, July 6-10, 1998, pp. 1976-1978.

[53] Q. P. Remund and D. G. Long, "Sea ice mapping algorithm for QuikScat and SeaWinds," in Proc. IGARSS'98, Seattle, WA, July 6-10, 1998, pp. $1686-1688$.

[54] _ "Polar sea ice extent mapping using Ku-band scatterometer data," J. Geophys. Res., to be published.

[55] _ " "Optimization of SIRF for NSCAT," BYU Microwave Earth Remote Sensing Lab., Provo, UT, MERS Tech. Rep. 97-003, 1997.

[56] Q. P. Remund, D. S. Early, and D. G. Long, "Azimuthal modulation of Ku-band scatterometer $\sigma^{\circ}$ over the antarctic," BYU Microwave Earth Remote Sensing Lab., Provo, UT, MERS Tech. Rep. 97-02, p. 24, 1997.

[57] F. Remy, Ledroit, and J. F. Minster, "Katabatic wind intensity and direction over Antarctica derived from scatterometer data," Geophys. Res. Lett., vol. 19, pp. 1021-1024, 1992.

[58] E. Rignot, "Backscatter model for the unusual radar properties of the Greenland ice sheet," J. Geophys. Res., vol. 100, no. E5, pp. 9389-9400, 1995.

[59] H. Rott, "Synthetic aperture radar capabilities for glacier monitoring demonstrated with Seasat SAR data," Z. für Gletscherkunde u. Glazialgeol., vol. 16, pp. 255-266, 1980

[60] H. Rott, K. Sturm, and H. Miller, "Active and passive microwave signatures of antarctic firn by means of field measurements and satellite data," Ann. Glaciol., vol. 17, pp. 337-343, 1993.

[61] H. Rott, P. Skvarca, and T. Nagler, "Rapid collapse of northern Larsen ice shelf, Antarctica," Science, vol. 271, pp. 788-792, 1996.

[62] P. Skvarca, "Changes and surface features of the Larsen ice shelf, Antarctica, derived from Landsat and Kosmos mosaics," Ann. Glaciol. vol. 20, no. 6, 1994

[63] S. Stammerjohn, R. Smith, M. R. Drinkwater, and X. Liu, "Variability in sea-ice coverage and ice-motion dynamics in the PAL LTER study region west of the Antarctic peninsula," in Proc. IGARSS'98, Seattle, WA, July 6-10, 1998, pp. 1434-1436.

[64] C. T. Swift, P. S. Hayes, J. S. Herd, W. L. Jones, and V. E. Delnore, "Airborne microwave measurements of the southern Greenland ice sheet," J. Geophys. Res., vol. 90, no. B2, pp. 1983-1994, 1985.

[65] W. B. Tucker, D. K. Perovich, A. J. Gow, W. F. Weeks, and M. R. Drinkwater, "Physical properties of sea ice relevant to remote sensing," in Microwave Remote Sensing of Sea Ice, F. D. Carsey, Ed. American Geophysical Union, Geophysical Monograph 28, ch. 2, pp. 9-28, 1992.

[66] M. R. Wensnahan, "Evolution of the passive microwave signature of thin sea ice," unpublished Ph.D. dissertation, Univ. Washington, Seattle, p. $142,1995$.

[67] R. S. Williams, Jr., D. K. Hall, and C. S. Benson, "Analysis of glacier facies using satellite techniques," J. Glaciol., vol. 37, no. 125, pp. 120-128, 1991.

[68] D. P. Winebrenner, D. G. Long, and B. Holt, "Automatable observation of seasonal transitions on Arctic sea ice using synthetic aperture radar," in Recent Advances in the Analysis of SAR for Studies in the Polar Oceans, C. Tsatsoulis and R. Kwok, Eds. Berlin, Germany: SpringerVerlager, 1998, pp. 129-144
[69] V. R. Wismann and K. Boehnke, "Monitoring snow properties on Greenland with ERS scatterometer and SAR," in 3rd ERS Symp., Florence, Italy, Mar. 1997.

[70] V. R. Wismann, K. Boehnke, and C. Schmullius, "Monitoring ecological dynamics in Africa with the ERS-1 scatterometer," in Proc. IGARSS'95, pp. $1523-1525$.

[71] S. H. Yueh, R. Kwok, S. Lou, and W. Tsai, "Sea ice identification using dual-polarized Ku-band scatterometer data," IEEE Trans. Geosci. Remote Sensing, vol. 35, pp. 560-569, May 1997.

[72] H. J. Zwally, A. C. Brenner, J. A. Major, R. A. Bindschadler, and J. G. Marsh, "Growth of the Greenland ice sheet," Science, vol. 246, pp. $1587-1591,1989$.

David G. Long (S'79-M'82-SM'98), for a photograph and biography, see this issue, p. 1541 .

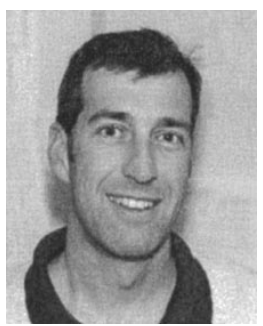

Mark R. Drinkwater (M'88) received the B.Sc. degree with honors from Durham University, U.K. in 1984, specializing in remote sensing in glaciology and a Council of Europe Diploma in remote sensing in engineering from the University of Dundee, Scotland, in 1984. For his doctorate research he studied at Emmanuel College and Scott Polar Research Institute at the University of Cambridge, U.K. He received the Ph.D. degree in geophysics in 1988, for a thesis entitled "Radar Altimetric Studies of Polar Ice."

Between 1987 and 1988, he worked in Cambridge as a Consulting Research Scientist with Polar Oceans Associates, a U.K. Division of Science Applications International Corporation. In 1988, he was awarded a National Research Council Resident Research Associateship, and until 1990, worked in the Polar Oceanography Group at the Jet Propulsion Laboratory (JPL), California Institute of Technology, Pasadena. Since 1990, he has been a Research Scientist in the JPL Ocean Sciences Research Element, working on several international projects with NASA, ESA, CSA, and NASDA. He has published more than 40 refereed journal articles, several book chapters, and more than 40 conference papers. His professional interests involve microwave remote sensing of the polar oceans and terrestrial ice sheets. Recent focuses include geophysical data extraction, inverse electromagnetic scattering, and in coupling EM and thermodynamic models with massively parallel general circulation models for large-scale estimates of surface fluxes of heat and salt in the polar oceans.

Dr. Drinkwater is a member of the International Glaciological Society and the IEEE Geoscience and Remote Sensing Society, and is presently an Associate Editor of AGU's Journal of Geophysical Research, Oceans. 